Check for updates

Cite this: RSC Adv., 2019, 9, 24401

\title{
A review of modification of carbon electrode material in capacitive deionization
}

\author{
Yutuo Cheng, $\dagger^{\mathrm{ab}}$ Zhiqi Hao, $\dagger^{\mathrm{ab}}$ Changrun Hao, ${ }^{\mathrm{ab}}$ Yu Deng, ${ }^{\mathrm{ab}}$ Xingying $\mathrm{Li}^{\mathrm{ab}}$ \\ Kexun Li (D) *ab and Yubo Zhao*ab
}

\begin{abstract}
Capacitive deionization (CDI) technology has attracted wide attention since its advent and is considered as one of the most promising technologies in the field of desalination and ion recycling. It is constructed with an electric field by applying a low voltage of direct-current to make ions migrate directionally in solution to achieve the purpose of ion separation and removal. The performance of CDI is heavily dependent on the electrode material. Carbon is widely used as CDI electrode material because of its lower price and better stability. To enhance the adsorption capacity, extensive research efforts have been made for the modification of carbon material. In this review, we enumerate and analyze four modification methods of carbon material including element doping, metal oxide modification, chemical treatment and surface coating. The influence of each modification method on CDI performance is concluded in the perspective mechanism and some constructive advice is put forward on how to effectively enhance the performance of CDI by the decoration of carbon materials.
\end{abstract}

Received 12th June 2019

Accepted 21st July 2019

DOI: $10.1039 / \mathrm{c} 9 \mathrm{ra0} 4426 \mathrm{~d}$

rsc.li/rsc-advances

$\mathrm{RO}$, indicating that economic efficiency of CDI is also applicable in high concentration solutions. By changing the preparation methods and experimental conditions, the adsorption capacity of different ions can also be changed and the goal of specific adsorption can be achieved. Seo et al. studied the adsorption force of CDI on divalent ion by preparing graphene nanoflakes. ${ }^{10}$ In terms of difficulty of ion removal, AlMarzooqi et al. proved that CDI can remove $85 \%$ of divalent ions in water, showing the potential for drinking water treatment. ${ }^{11}$ CDI has been proven to be available in brackish water desalination. ${ }^{7-12}$ In addition, CDI can also be used in medicine, chemistry, microbial fuel cells and so on. ${ }^{13-16}$

Theories and experimental results both showed that porous carbon materials generally possessed high specific surface areas and excellent capacitive properties, which led to better CDI performance. CDI theory is similar to that of supercapacitors. ${ }^{7}$ Up to now, the core of CDI technology is to seek the maximum adsorption capacity per unit mass and the minimum energy loss power from the perspective of theory and properties. In terms of experience and theory, the ideal CDI electrode materials require the following properties: (1) large specific surface area for adsorption; (2) the stability and applicability of $\mathrm{pH}$, voltage and ion concentration in different areas; (3) high speed ion mobility, i.e. conductivity; (4) good plasticity and expandability; (5) suitable pore size distribution structure; (6) abundant and readily available natural or artificial low-cost materials; (7) stable and reusable physical and chemical properties.

With the rapid development of CDI electrode materials, research work emerges endlessly. In previous literature,

\footnotetext{
${ }^{a}$ The College of Environmental Science and Engineering, Nankai University, Tianjin 300071, China.E-mail: likx@nankai.edu.cn; 1244174212@qq.com

${ }^{b}$ MOE Key Laboratory of Pollution Processes and Environmental Criteria, Tianjin Key Laboratory of Environmental Technology for Complex Trans-Media Pollution, Nankai University, Tianjin 300071, China

$\dagger$ Author Y. Cheng and Z. Hao contribute equally to this work.
}

\begin{abstract}
che
\end{abstract}


researchers have analyzed their progress in terms of activated carbon, ${ }^{17-19}$ mesoporous carbon, ${ }^{20-22}$ carbon aerogels, ${ }^{23,24}$ carbon nanotubes, ${ }^{25-27}$ graphene, ${ }^{28,29}$ etc., and reviewed the various carbon-based materials ${ }^{8,30}$ as well as graphene materials ${ }^{31}$ for CDI. However, there is still a review gap in the field of modification of carbon electrode materials. To fill this vacancy, we provide a comprehensive summary of common modification methods in the aspects of element doping, metal oxide doping and polymers, and put forward some prospects. This article summarizes the existing successful modification methods of carbon electrode materials in CDI.

\section{History of CDI materials}

Compared with other traditional desalination methods, CDI is a new effective technology. ${ }^{8}$ Studies on CDI can trace back to the 1960s and the conception was first reported by Murphy and Caudle. They designed a flow through mode whose electrode sheets consisted of porous activated carbon electrodes for water desalination. Then in 1970s, Johnson et al. studied the reversible process of CDI and proposed a reversible electrosorption model. In this theory, ions hidden in the electrode sheets could be released by removing electrical field..$^{32}$ On the other hand, they gave a conclusion that the application of high-surface area electrodes would be beneficial to efficient desalination. However, there are still some limitations in carbon materials, such as poor stability, single composition, and too irregular structure. Scientists have tried abundant modification methods of carbon materials in the course of past few decades to seek more suitable modified materials for practical production. Thus, more and more materials such as carbon nanotubes, carbon aerogel, ordered mesoporous carbons, carbon nanofiber and graphene have been applied to CDI technology, which lead to a great boost in the field. ${ }^{18}$ Here some typical materials will be introduced with their properties and application examples.

Generally, activated carbon (AC) is the most widely used electrode material for CDI electrode because of its highercapacity of environmental contaminants and cheaper price. ${ }^{33}$ But lower conductivity and higher electrical transfer resistance limit its further development in CDI. ${ }^{34} \mathrm{AC}$ is usually combined with binders and conductive additives to fabricate CDI electrode. Hou et al. found that ten percent of PVDF (a kind of binder) could achieve a better result in CDI experiment. ${ }^{35}$ Furthermore, some chemical modification methods by introducing hydrophilic reactive functional group can also greatly improve the electrosorption capacity of activated carbon electrodes. ${ }^{36}$

Carbon Nanofiber (CNF) is a fibrous one-dimension carbon nanomaterial, which could be obtained by electrospinning. In recent years, more and more people have focused concerns on the application in the field of supercapacitors for its high surface area, high electrical conductivity and unique filamentous structure. ${ }^{37}$ In 2014, Chen et al. fabricated phenolic resinbased CNF through electrospinning and one-step carbonization and applied the electrode materials to CDI. ${ }^{38}$

Carbon aerogel (CA) possesses unique strengths such as good conductivity, continuous and favorable pore distribution, as well as high surface area. ${ }^{39}$ In 1990, Farmer et al. discovered carbon aerogel and applied this material to CDI electrodes. From then on, searching new carbon materials with a high specific surface area has become a focus of concern among scientist. ${ }^{40}$ Although carbon aerogel has unique good properties, the complex processing technology and high cost limit its development.

Carbon nanotube (CNT), a kind of one-dimensional nanomaterial with hollow structure, is well known for its strong active functional groups and proper pore structure. In 2005, carbon nanotubes were first used for CDI according to Dai and his team's study. ${ }^{41}$ Arvind et al. found amazing adsorption effect by opening the termination of carbon nanotubes involve oxidation to get more organic functional groups. ${ }^{42}$

Graphene is a new two-dimensional carbon nanomaterial with single atomic layer, possessing great development potentiality. Graphene was first gained by Andre et al. in 2004 and was used into CDI in 2009. It has some derivatives such as graphene oxide and reduced graphene oxide which are usually loaded on other electrode materials. Yu et al. incorporated graphene oxide with carbon nanofibers. The desalination performance was improved for the enhancement of electrical conductivity and mesoporosity ratio. ${ }^{43}$

Ordered mesoporous carbons (OMCs), possessing ordered pore size and less ion transfer resistance, are promising candidate for CDI electrode. Zou et al. first adopted OMCs to CDI. They found this electrode showed better ion removal performance and faster desorption speed compared with activated carbon.$^{44} \mathrm{Li}$ et al. prepared mesoporous carbon electrode with larger surface area by adding $\mathrm{NiSO}_{4} \cdot 6 \mathrm{H}_{2} \mathrm{O}$, which performed a better electrosorption performance. ${ }^{45}$

As the research continues, researchers found that excellent CDI electrode materials require the properties of large specific surface area, suitable pore size, high hydrophilicity and high conductivity. ${ }^{31,46}$ To improve those properties, various modification methods have been developed. The timeline is shown in Table 1.

\section{Modification methods}

\subsection{Heteroatom doping}

Carbon materials, with the advantages of low cost, light weight, large specific surface area, corrosion resistance, oxidation resistance, excellent ductility and porous structure, occupy a dominant position in CDI electrodes. However, due to their super high stability and structural framework, carbon materials often have a single element type. That makes it difficult for CDI electrode materials to break through in terms of adsorption capacity, rate and types. Fortunately, the known organic species are far more than inorganic species, and carbon is the most basic element of the organic structure skeleton, that is to say, it has strong plasticity and compatibility. That makes it possible for scientists and researchers to dope other ions or elements into carbon materials to improve their electrosorption performance. Actually, heteroatom doping is one of the most used modification methods for carbon materials. It is worth mentioning that experiments showed that not all elements are 
Table 1 History of CDI materials

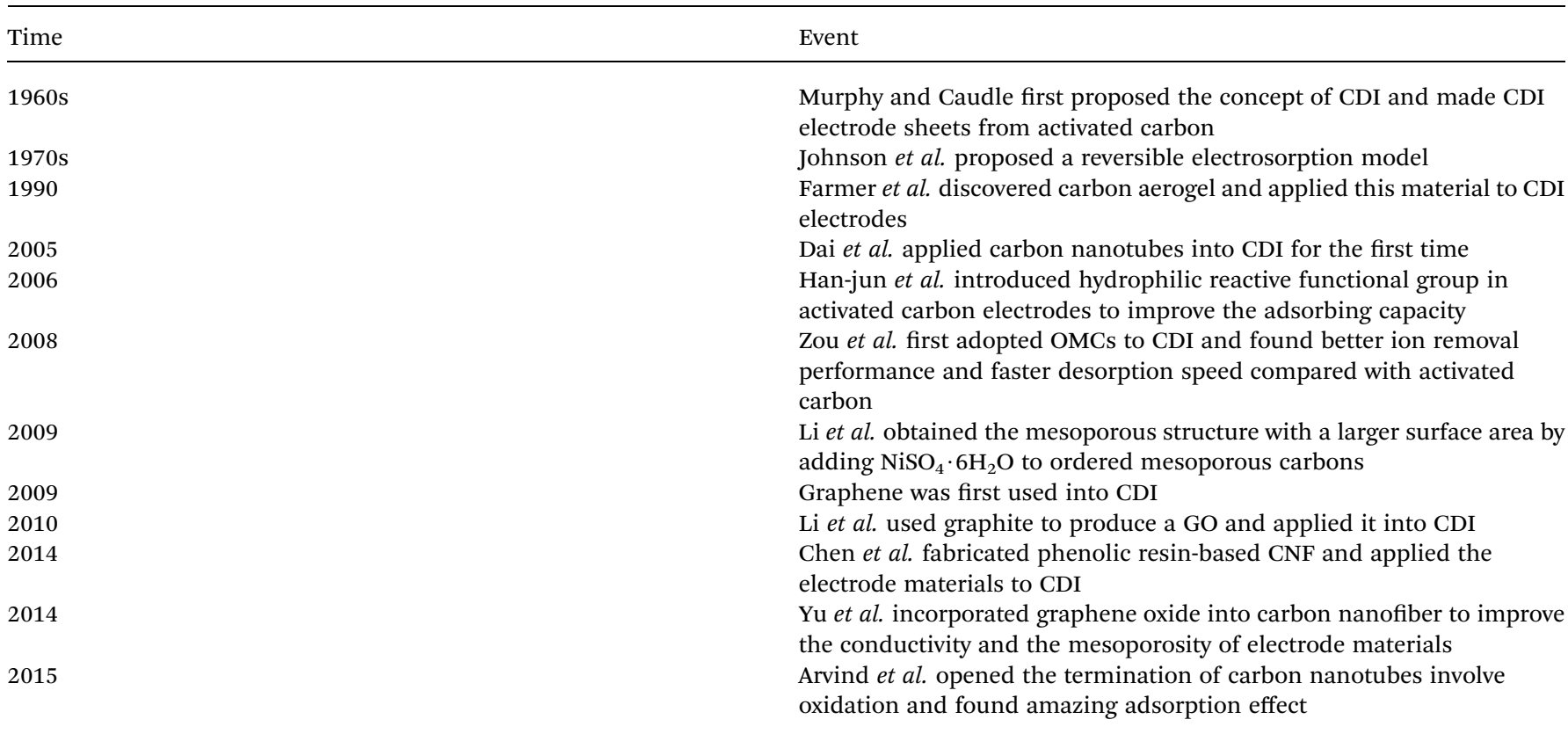

suitable for element doping. Non-metallic elements, such as $\mathrm{N}$, $\mathrm{P}, \mathrm{S}$ and $\mathrm{Cl}$ are commonly selected and calcined with carbon materials at high temperatures to prepare element doped electrodes. Several common heteroatom doping methods are as followed.

3.1.1. N-doped carbon material. Owing to the unique valence electron layer structure, nitrogen can form ionic bonds or covalent bonds with other atoms. This property makes it widely used in the field of CDI electrode modification. The existent forms of nitrogen in carbon materials can be divided into chemical nitrogen and structural nitrogen. Chemical nitrogen exists in the form of surface functional groups, such as amino and nitrite, while structural nitrogen atoms enter the framework of carbon materials, such as pyridine nitrogen and quaternary nitrogen. Nitrogen atoms in carbon skeleton not only optimize the pore structure, but also increase the chemical reactivity and electron transport properties of carbon atoms. ${ }^{47}$ Chemical nitrogen doping is able to improve the hydrophilicity of carbon materials, thus enhancing their catalytic and adsorption capacities. ${ }^{48}$ Moreover, nitrogen doping can increase the active sites of carbon materials, make metal particles evenly dispersed on the surface and reduce the amount of precious metals. It can also increase the adsorption capacity of porous carbon materials for $\mathrm{CO}_{2}$ and $\mathrm{H}_{2} \cdot{ }^{49,50}$ In conclusion, nitrogen doping can improve the comprehensive properties of carbon material and expand its application field.

Usually, there are three methods to dope nitrogen into carbon materials. The first one is to use nitrogen-containing monomers, such as melamine, pyrrole, sucrose and polyaniline, as precursors to prepare nitrogen-containing polymers which are then heat-treated. Directly heating nitrogencontaining biomass materials or wastes is the second way. The last one is to use $\mathrm{NH}_{3}$ or $\mathrm{CO}\left(\mathrm{NH}_{2}\right)_{2}$ as nitrogen source to post-treat the material, so that specific nitrogen-containing groups will be introduced into the carbon material. The effects of different nitrogen doping methods on electrochemical properties and electroadsorption capacities of carbon materials will be described in detail below.

When nitrogen doping is used in capacitive deionization, it can effectively enlarge the surface pore size of carbon materials, i.e. enlarging the specific surface area. High specific surface area is one of the most remarkable features of carbon materials, which represents high adsorption capacity. Hence, nitrogen contend is a major consideration of characterization. Zhao et $a .^{51}$ used polystyrene (PS) as hard template, and dopamine hydrochloride as carbon and nitrogen sources to prepare nitrogen-doped porous carbon microspheres $(\mathrm{N}$ PHCS). Its uniform, spherical and hollow carbon structure was observed in field emission scanning electron microscopy (SEM) and transmission electron microscopy (TEM) images (Fig. 1(a)-(c)). The nitrogen content, determined by X-ray photoelectron spectroscopy (XPS), was 2.92\% (Fig. 1(d)). The result of the SAC curve and current transient of N-PHCS electrodes in $500 \mathrm{mg} \mathrm{L}^{-1} \mathrm{NaCl}$ solution also indicated that its electrochemical performance was fantastic (Fig. 1(e)). A $500 \mathrm{mg} \mathrm{L}{ }^{-1} \mathrm{NaCl}$ aqueous solution was treated at a flow rate of $40 \mathrm{~mL} \mathrm{~min}^{-1}$ at $1.4 \mathrm{~V}$. The specific electrosorption capacity (SAC) was $12.95 \mathrm{mg} \mathrm{g}^{-1}$ and its stability was perfect. Li et al. ${ }^{52}$ prepared similar nitrogen-doped materials. Nitrogen-doped cluster porous carbon materials (NCPC) with layered hollow nanostructures were fabricated under various temperatures by carbonizing dopamine/nano-ZnO composites. They possessed good wettability interconnection layer structure, enabling rapid ion binarization. Among them, the sample carbonized at $900{ }^{\circ} \mathrm{C}$ (NCPC-900) showed the best porous structure. Its specific surface area was $1357 \mathrm{~m}^{2} \mathrm{~g}^{-1}$ and the maximum adsorption capacity was $11.98 \mathrm{mg} \mathrm{g}^{-1}$. In terms of nitrogen content, NCPC-700 reached the highest of 9.2\%. Besides, Liu 

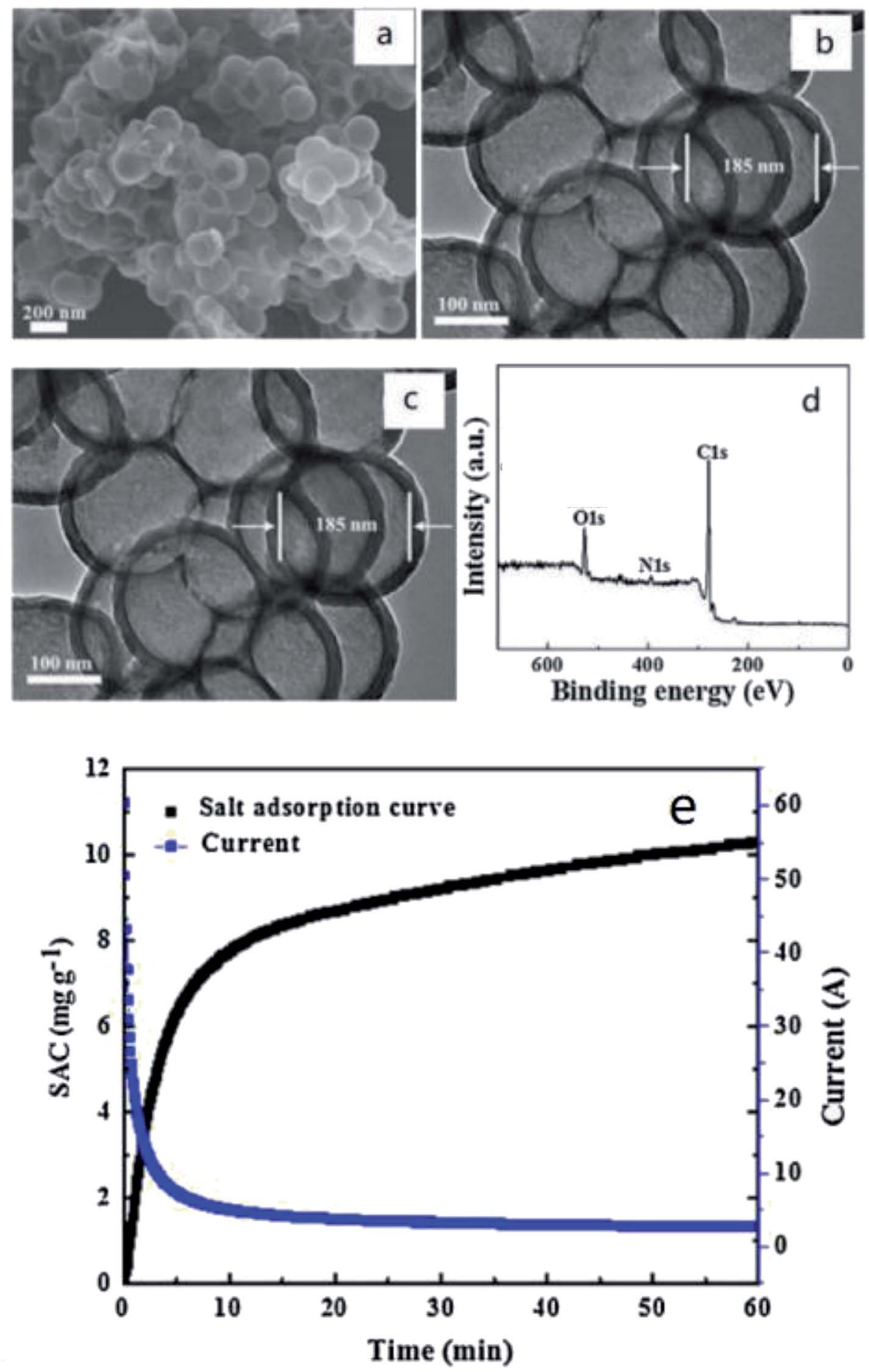

Fig. 1 (a) SEM (b) TEM and (c) HRTEM images of the N-PHCS; (d) XPS spectra of the N-PHCS sample; (e) the SAC curve and current transient of $\mathrm{N}$-PHCS electrodes in $500 \mathrm{mg} \mathrm{L}^{-1} \mathrm{NaCl}$ solution at the voltage of $1.2 \mathrm{~V}$ with a flow rate of $40 \mathrm{~mL} \mathrm{~min}^{-1}$; reproduced with permission from ref. 51 .

et al. ${ }^{53}$ prepared nitrogen-doped porous carbon microspheres (NPCS) by microblog-assisted rapid preparation method. In this process, sucrose was used as a precursor. Through a series of characterization and experimental measurements, it was found that NCPS treated at $1000{ }^{\circ} \mathrm{C}$ possessed the highest electroadsorption capacity of $14.91 \mathrm{mg} \mathrm{g}^{-1}$ in $1000 \mathrm{mg} \mathrm{L}^{-1}$ treated solution.
Gao et al. ${ }^{54}$ synthesized graphene polyhedrons directly from pyrolytic imidazolate skeleton (ZIF-8). Characterization results showed that it had close SP-2 skeleton edges. When compared with carbon polyhedrons (CPs) and nitrogen doped carbon polyhedrons (NCPs), besides the benefits of $1134 \mathrm{~m}^{2} \mathrm{~g}^{-1}$ remarkable specific surface area and considerable graphitization degree, the conductivity and cycling stability of nitrogen- 
doped graphitic carbon polyhedrons (NGCP) were also distinguished. In CDI experiment, NGCP exhibited a desalination capacity of $17.73 \mathrm{mg} \mathrm{g}^{-1}$ with $500 \mathrm{mg} \mathrm{L}^{-1} \mathrm{NaCl}$ solution at the voltage of $1.4 \mathrm{~V}$. Duan et al. ${ }^{55}$ and Liu et al. ${ }^{56}$ also applied ZIF-8 to the preparation of analogous carbon materials and obtained good results (Fig. 2). The above experimental results proved that nitrogen doping was an effective method to improve the electrosorption performance as well as recycling stability of carbon materials.

In addition, calcination of nitrogen-containing biomass at high temperature under pure nitrogen condition is a common method to prepare carbon materials. It can effectively determine the pore size of carbon materials and the distribution of nitrogen elements in the materials. Classically, Zhao et al. ${ }^{57}$ fabricated nitrogen-doped porous carbon (NPC) by simple pyrolysis method, using soybean hull as raw material and $\mathrm{KHCO}_{3}$ as catalyst. Then NPC sulfonate group was functionalized in aryl diazonium salt solution, leading to a final specific surface area of $844.0 \mathrm{~m}^{2} \mathrm{~g}^{-1}$ and nitrogen content of $1.66 \mathrm{at} \%$. The electrosorption capacity of this material was $15.8 \mathrm{mg} \mathrm{g}^{-1}$, and the adsorption rate was $0.37 \mathrm{mg}(\mathrm{g} \text { min })^{-1}$ due to the high surface negative charge density.

The last kind of nitrogen doping aims at introducing specific nitrogenous groups, such as $\mathrm{NH}_{3}$ and $\mathrm{NR}_{4}$, onto the surface of carbon materials. Yang et al. ${ }^{58}$ used aryl diazonium salt solution and acetone mixed with APTEs to introduce $-\mathrm{SO}_{3}{ }^{2-}$ and $-\mathrm{NH}_{3}{ }^{+}$ groups into nanotubes to overcome co-ion effect. Characterizations and electrosorption results indicate that the functionalized-CNTs electrodes enhanced the salt-removing performance. Later, Gao et al. ${ }^{59}$ introduced ethylenediamine into the surface of microporous spectracarb carbon cloth and used it as the cathode electrode. Meanwhile, the anode carbon material was treated with nitric acid to increase its negative surface charge. The maximum adsorption capacity was $5.3 \mathrm{mg}$ $\mathrm{g}^{-1}$ at $1.1 \mathrm{~V}$ working voltage and characterization results showed that the functional groups derived from ethylenediamine increased the microporosity of carbon materials. In the latest research, Ahmed G. et al. ${ }^{60}$ modified activated graphene electrodes with polyatomic ions $\left(\mathrm{NR}_{4}{ }^{+}\right)$. Carboxymethyl cellulose (CMC) was negatively charged and quaternary ammonium cellulose (QMC) was used as the disinfectant. The obtained materials asym-QC-3DAPGr (3DPGr: 3D porous graphene) were treated with $300 \mathrm{mg} \mathrm{L}{ }^{-1} \mathrm{NaCl}$ solution at $1.4 \mathrm{~V}$ cell voltage. And adsorption capacity per unit is up to $18.43 \mathrm{mg} \mathrm{g}^{-1}$. In another aspect, the non-toxic water-soluble adhesive also reduces the interface resistance and improves the flexibility of the electrode.

Nitrogen doping is often combined with graphene. Graphene is a two-dimensional carbon nano-material with hexagonal honeycomb lattice composed of carbon atoms and $\mathrm{sp}^{2}$ hybrid orbital. Its excellent conductivity and pore structure make it a new favorite of electrodes choosing in CDI, and it is often associated with nitrogen doping to form two-dimensional
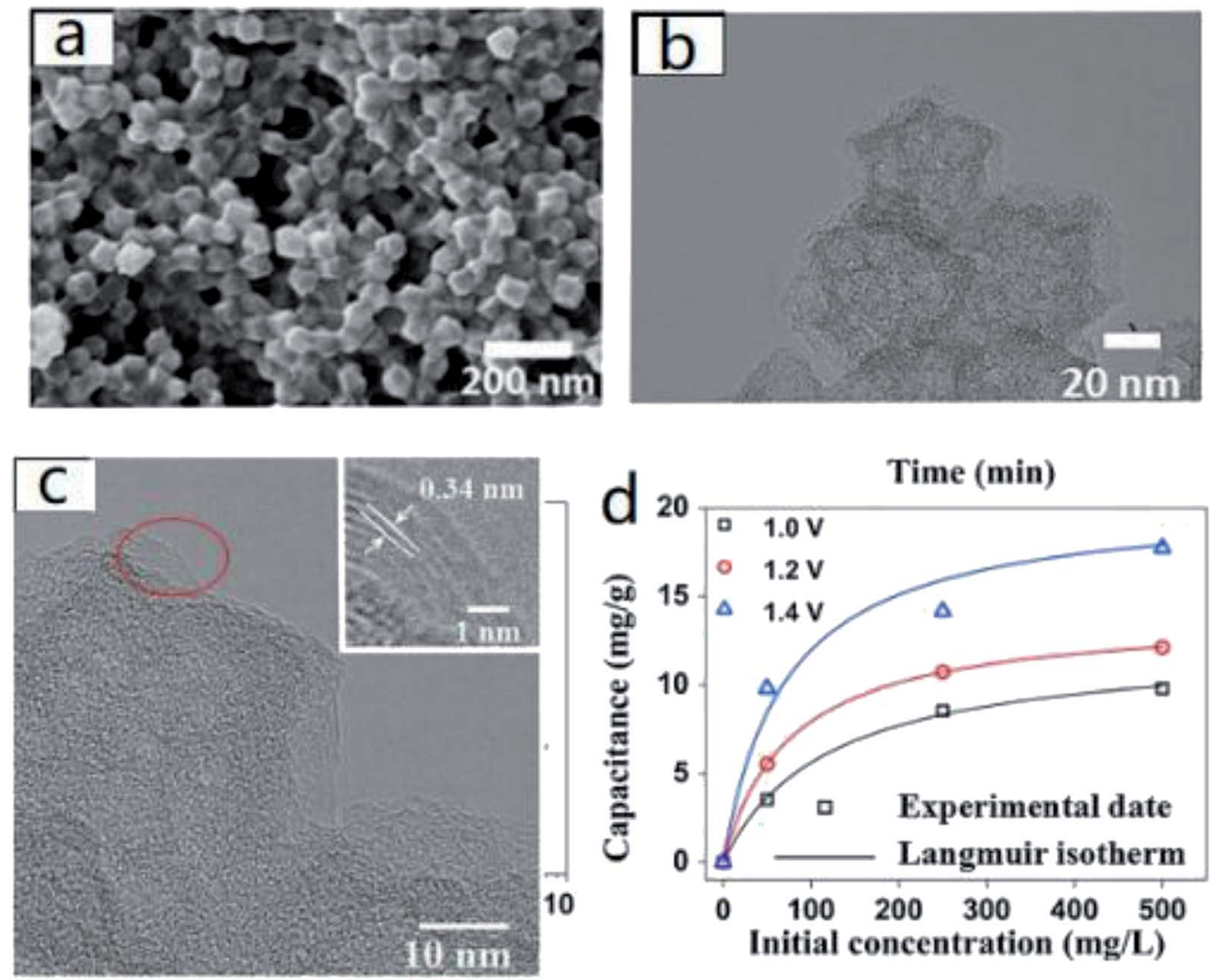

Fig. 2 (a) The SEM (b) TEM and (c) HRTEM image of NGCPs; (d) electrosorption capacitance and Langmuir isotherm of NGCPs at various voltage in $\mathrm{NaCl}$ solutions with initial concentration ranging from 50 to $500 \mathrm{mg} \mathrm{L}^{-1}$. Reproduced with permission from ref. 54 . 
carbon nanomaterials. In fact, as early as $2015, \mathrm{Xu}$ et al. ${ }^{61}$ have prepared a novel nitrogen-doped graphene sponge (NGS), which has high specific surface area of $526.7 \mathrm{~m}^{2} \mathrm{~g}^{-1}$, and its designed structure can be also fabricated. Eventually, when treated with $500 \mathrm{mg} \mathrm{\textrm {L } ^ { - 1 }} \mathrm{NaCl}$ solution, the adsorption capacity attained $21 \mathrm{mg} \mathrm{g}^{-1}$, which was also the highest at that time. In the same year, Amiri et al. ${ }^{62}$ published an article to demonstrate that highly-crumpled nitrogen-doped graphene and highly-crumple and few-layered graphene have enormous potentiality in industry desalination. Liu et $a .^{63}$ then applied this material to the rapid removal of heavy metal ions $\left(\mathrm{Pb}^{2+}, \mathrm{Cd}^{2+}, \mathrm{Cu}^{2+}, \mathrm{Fe}^{2+}\right)$ in water, obtaining a removal rate of $90 \%$ in the range of $0.05-$ $200 \mathrm{ppm}$ and perfect recycling abilities. In the latest research, Zhou et al. ${ }^{64}$ prepared two-dimensional sandwich graphene/ nitrogen-doped carbon nanoparticles composites using graphene/porous $\mathrm{SiO}_{2}$ composite as a template, ethylene diamine and carbon tetrachloride as carbon sources. It exhibits high capacitance up to $189 \mathrm{~F} \mathrm{~g}^{-1}$ at a current density of $0.1 \mathrm{~A} \mathrm{~g}^{-1}$. This further proves that nitrogen-doped graphene has broad application prospects in the field of CDI.

3.1.2. Multielement doping. In addition to $\mathrm{N}$, the most commonly used element are $\mathrm{S}$ and $\mathrm{P}$ to modify carbon material. In the latest research, Ma et al. ${ }^{65}$ introduced $\mathrm{S}$ atoms into the graphene skeleton and proved that this operation can effectively improve the capacitance performance of graphene. A few years early, Porada et al. $^{66}$ used salt template synthesis to prepare biomass precursors and sulfur-doped microporous carbon. Among their materials, NDC-Cs-900 (NDC: nitrogen doped carbon, Cs: Cs acetate) shew the best performance. The maximum specific surface area was $2830 \mathrm{~m}^{2} \mathrm{~g}^{-1}$ and the adsorption capacity could reach up to $15.0 \mathrm{mg} \mathrm{g}^{-1}$ at the voltage of $1.2 \mathrm{~V}$. In addition, they also compared it with the undoped $\mathrm{P}$ carbon material and found that heteroatom-doped carbon material was a promising CDI material. It also indicated that the high heteroatom content may be related to low charge efficiency. Meanwhile, they are often closely associated with nitrogen doping. Wang et al. introduced sulfur doping into carbon fibers and made pore and graphitized edges, which not only improved cycle stability, but also facilitated fast capacitive sodium storage.

Apart from sulfur, phosphorus is another doping element that is often used in carbon modification. Li et al. ${ }^{67}$ compared the $\mathrm{P}$ and none element doped carbon nanofibers aerogels in $1000 \mathrm{mg} \mathrm{L}^{-1} \mathrm{NaCl}$ solution, and the adsorption capacity of undoped $\mathrm{P}$ was $12.81 \mathrm{mg} \mathrm{g}^{-1}$ while that of (P)-doped carbon nanofiber aerogels (P-CNFA) was $16.20 \mathrm{mg} \mathrm{g}^{-1}$. In addition, the nitrogen and phosphorus dual doped graphene aerogels were prepared to expand the capacitance and cycling stability of the materials. In this way, Li et al. ${ }^{68}$ greatly improved the performance of carbon anodes used in the construction of electrochemical capacitors. Experiments show that the double doping of nitrogen and phosphorus makes graphene aerogel (NPGA) have high sodium storage capacity and wide application prospect in CDI field, and its cycling stability is excellent. On the level of practical application, Han et al. ${ }^{69}$ firstly used phytic acid as $\mathrm{P}$ source, chitosan as $\mathrm{N}$ source, mixed with gallic acid to deal with graphene oxide and succeed in preparing highly hydrophilic N, P co-doped three-dimensional hierarchical carbon architectures. Due to its three-dimensional structure, the material has a high adsorption capacity of $26.8 \mathrm{mg} \mathrm{g}^{-1}$ at an applied voltage of $1.2 \mathrm{~V}$.

To some extent, it seems that the more types of element were used to dope, the more remarkable the effect is. Of course, it is also inseparable from the reasonable element collocation and the selection of appropriate element sources. In 2018, Zhang et $a .^{70}$ succeeded in making $\mathrm{N}, \mathrm{P}, \mathrm{S}$ co-doped hollow carbon polyhedral. They chose poly(cyclotriphosphazene-co-4,4'-sulfonyldiphenol) as carbon sources and N, P, S co-doping sources, ZIF-8 as structural templates, which also acted as additional Ndoping sources. TEM results showed that ZIF-8@PZS-C (poly(cyclotriphosphazene-co-4,4'-sulfonyldiphenol) coated zeolitic imidazolate framework-8) owned fabulous pore structure (Fig. 3(a) and (b)). Ultimately, the super-high adsorption capacity of $22.19 \mathrm{mg} \mathrm{g}^{-1}$ was achieved in the treatment of $500 \mathrm{mg} \mathrm{L}^{-1} \mathrm{NaCl}$ solution (Fig. 3(c)). It is reasonable to believe that more and more attention will be paid to multielement doping.

3.1.3. Ion-doped carbon material. Aside from the common doping of non-metallic elements, ion doping refers to dope metal elements such as $\mathrm{Li}^{+}, \mathrm{Fe}^{3+}$ and $\mathrm{Cl}^{-}$into carbon materials. Generally speaking, ion doping can effectively improve the specific capacitance of material, reduce the charging resistance of the composite electrode and improve its stability and regeneration efficiency, and enhance the electrochemical performance of the composite. Those functions indicate ion doping an effective method to improve the electrosorption capacity of CDI electrode materials. Recently, Zhang et al. ${ }^{71}$
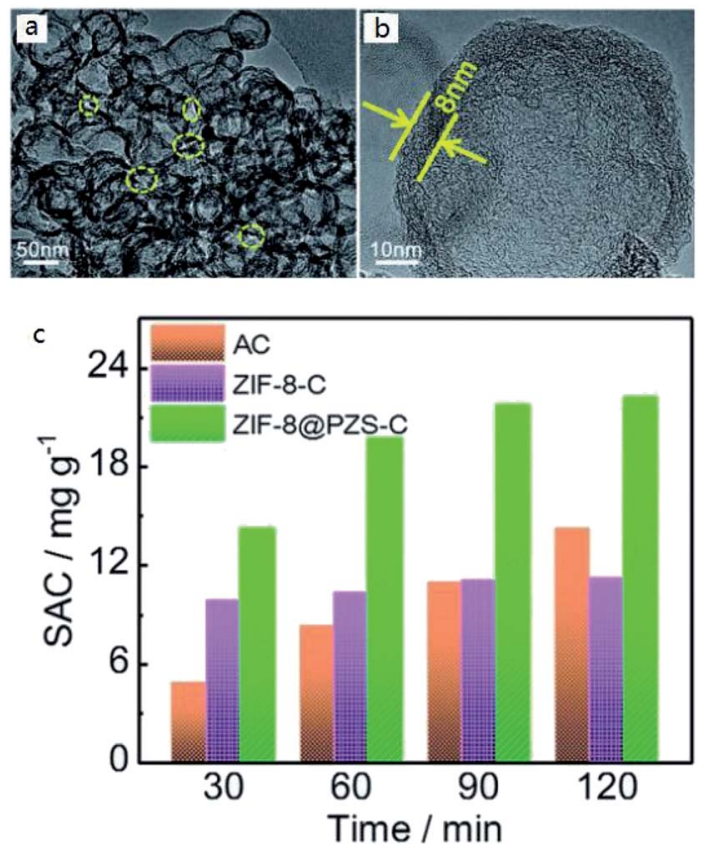

Fig. 3 (a) TEM images and (b) HRTEM image of ZIF-8@PZS-C; (c) plots of SAC vs. deionization time of various electrodes in $500 \mathrm{mg} \mathrm{L}^{-1} \mathrm{NaCl}$ solution at $1.2 \mathrm{~V}$ with a flow rate of $50 \mathrm{~mL} \mathrm{~min}{ }^{-1}$. Reproduced with permission from ref. 70 . 
prepared large-scale lithium ion-doped graphene/carbon nanofiber porous by electrospinning homogeneous $\mathrm{LiNO}_{3} /$ graphene oxide/polyacrylonitrile nanofibers and carbonize it at $900{ }^{\circ} \mathrm{C}$. Its porous structure provides high electrosorption capacity. The maximum efficiency can be as high as $87 \%$ and this material has broad application prospects in capacitive deionization.

In addition, ion-doped methods can be also associated with polypyrrole (PPy) and CNT. Chloride (Cl) and dodecylbenzene sulfonate (DBS) are both commonly used ion doping reagents. Normally, ion-doped CDI electrodes are affected by ion species, acidity and basicity in solution and experimental conditions. Wang et al. ${ }^{72}$ investigated the fouling characteristics of iondoped PPy/CNT composite electrodes in the process of CDI by a half cycle running mode. It was found that the addition of $\mathrm{Ca}^{2+}$ or $\mathrm{Fe}^{3+}$ in the solution would alkalize the regeneration process during desalination, thus affecting the adsorption performance of CDI. In the aspect of organic pollution, the addition of sodium humate significantly reduced the desalination performance of CDI batteries, because the high concentration of sodium humate would destroy the structure of the electrode layer and further destroy the stability of the electrode. Ma et $a l .{ }^{73}$ explored the effects of temperature and $\mathrm{pH}$ on iondoped PPy/CNT composite electrodes. Under the condition of $\mathrm{pH}=7, T=15{ }^{\circ} \mathrm{C}$, the adsorption capacity was the largest, reaching $75 \%$ or more. Meanwhile, strong acid and alkali will aggravate the oxidation reaction on the surface of the electrode, and the increase of temperature will lead to the hydrophilichydrophobic transition on the surface of the electrode, which results in the decrease of the adsorption capacity. In 2016, Cai et $a l .{ }^{74}$ measured the electrosorption capacity of PPy-DBS/CNT and $\mathrm{PPy}-\mathrm{Cl} / \mathrm{CNT}$ composite electrode. The electrosorption capacity is $40.8-72.36 \mathrm{mg} \mathrm{g}^{-1}$, which directly proves the strong electrosorption of ion-doped composite carbon materials. In another aspect, Cai inferred that the composite electrodes may have the good ability of ion selective adsorption for cations or anions.

\subsection{Metal oxide-modified carbon material}

For the reason of synergistic effects, the combination of carbon and metal oxides improves the specific capacitance, making them potential materials for capacitive deionization. ${ }^{75}$ Moreover, the addition of metal oxide can prominently change some physicochemical properties of carbon material, like wettability, surface area and zeta potential, which may contribute to the improvement of capacitive deionization performance.

3.2.1. $\mathrm{TiO}_{2}$-modified carbon material. $\mathrm{TiO}_{2}$ is an n-type semiconductor oxide, with qualities of high stability, high hydrophilicity, low cost as well as eco-friendliness. As early as 2003, $\mathrm{TiO}_{2}$ was utilized to modify carbon electrodes for CDI. ${ }^{17,76}$ By introducing $\mathrm{TiO}_{2}$, the wettability and electrochemical properties of carbon electrodes was reported to increase, resulting in the enhancement of electrosorption capacity. 77,78

High hydrophilicity of $\mathrm{TiO}_{2}$ is due to abundant hydroxyl groups on its surface. Those $\mathrm{Ti}-\mathrm{OH}$ groups can act as electrosorption sites on the surface of carbon electrode, which is beneficial to the CDI performance. Kim have et al. ${ }^{77}$ fabricated one of the $\mathrm{TiO}_{2}$ coated carbon electrodes. As shown in Fig. 4, the wettability of carbon electrode was highly enhanced by coating with $\mathrm{TiO}_{2}$. The $\mathrm{TiO}_{2}$ coated carbon electrode showed an electrosorption capacity of $17 \mathrm{mg} \mathrm{g}^{-1}$ which was nearly twice as high as that of carbon electrode. This improvement was resulted from the easier accessibility of ions and water from solution to the surface of electrode due to enhanced wettability. Recently, Kang et al. ${ }^{79}$ synthesized $\mathrm{TiO}_{2}$-modified activated carbon fibers (ACF). From the Nyquist impedance plots, it can be calculated that the value of charge transfer resistance decreased with $\mathrm{TiO}_{2}$ doping amount, implying that the introduction of $\mathrm{TiO}_{2}$ promotes ion migration and diffusion on the surface of carbon electrode. Consequently, the highest electrosorption capacity reached up to $10.6 \mathrm{mg} \mathrm{g}^{-1}$, which was $71.9 \%$ higher than that of the unmodified ACF electrode.

The strong hydrophobicity of CNT dramatically limits its CDI performance. With high hydrophilicity, $\mathrm{TiO}_{2}$ is promising for improving this situation. Li et al. ${ }^{80}$ reported a $\mathrm{TiO}_{2} / \mathrm{CNTS}$ composite electrode for CDI. This electrode displayed an enhanced electrosorption capacity of $4 \mathrm{mg} \mathrm{g}^{-1}$ which was twice as high as that of pristine CNTs. Feng et al. ${ }^{81}$ recently fabricated $\mathrm{TiO}_{2} / \mathrm{CNTs}$ membrane electrodes by atomic layer deposition method. The deposition of $\mathrm{TiO}_{2}$ was reported to transform CNT from strongly hydrophobic to hydrophilic. This composite electrode showed an improved desalination capacity of $5.09 \mathrm{mg}$ $\mathrm{g}^{-1}$ as well as good regeneration.

Cycling stability of CDI is challenged with peroxide formation and rapid oxidation of anodic electrode. ${ }^{82}$ To overcome this issue, Srimuk et al. ${ }^{83}$ presented a strategy by hybridizing nanocarbon particles with solgel-derived $\mathrm{TiO}_{2}$. This carbon/metal oxide hybrid showed $90 \%$ of the initial electrosorption capacity after 100 cycles, indicating an outstanding cycling stability. $\mathrm{TiO}_{2}$ was confirmed to prevent the formation of local peroxide by modifying redox reactions. In their subsequent research, $\mathrm{TiO}_{2}$-modified activated carbon electrodes were fabricated. ${ }^{84}$ The electrode loaded with $15 \mathrm{wt} \% \mathrm{TiO}_{2}$ displayed a considerable desalination capacity of $17.4 \mathrm{mg} \mathrm{g}^{-1}$ and a better cycling stability, attributed to favorable three-electron transfer reactions.

3.2.2. $\mathrm{MnO}_{2}$-modified electrode. Great specific capacitance (83.9 $\mathrm{F} \mathrm{g}^{-1}$ ) and electrosorption capacity $\left(5.4 \mathrm{mg} \mathrm{g}^{-1}\right)$, which illustrated the CDI electrosorption efficiencies of CMK-3, the hybrid electrodes and the deionization-regeneration profile as well as deionization-regeneration cycles of the $15 \mathrm{Mn} @ \mathrm{C}-400$ electrode, had been achieved by the use of $\mathrm{MnO}_{2}$ nanoparticles decorated mesoporous carbon, reported by Zhao et al. ${ }^{85}$ who raised a substantial enhancement compared with the normal ordered mesoporous carbon due to its well coexistence. Yang et al. suggested that the suitable pore size distribution property and high surface area may be the main contribution of the improvement. ${ }^{86}$ Besides the high capacitance $\left(204.7 \mathrm{~F} \mathrm{~g}^{-1}\right)$, an effective cation intercalation and high surface adsorption capability were proven to be extra superiority. And the $\mathrm{MnO}_{2}$ nanoparticles decorated anode made sure to avoid oxidation of carbon anodes, raised by $\mathrm{Wu}$ et al., who chose a $\mathrm{MnO}_{2}$ anode and an anion-selective quaternate poly(4- 

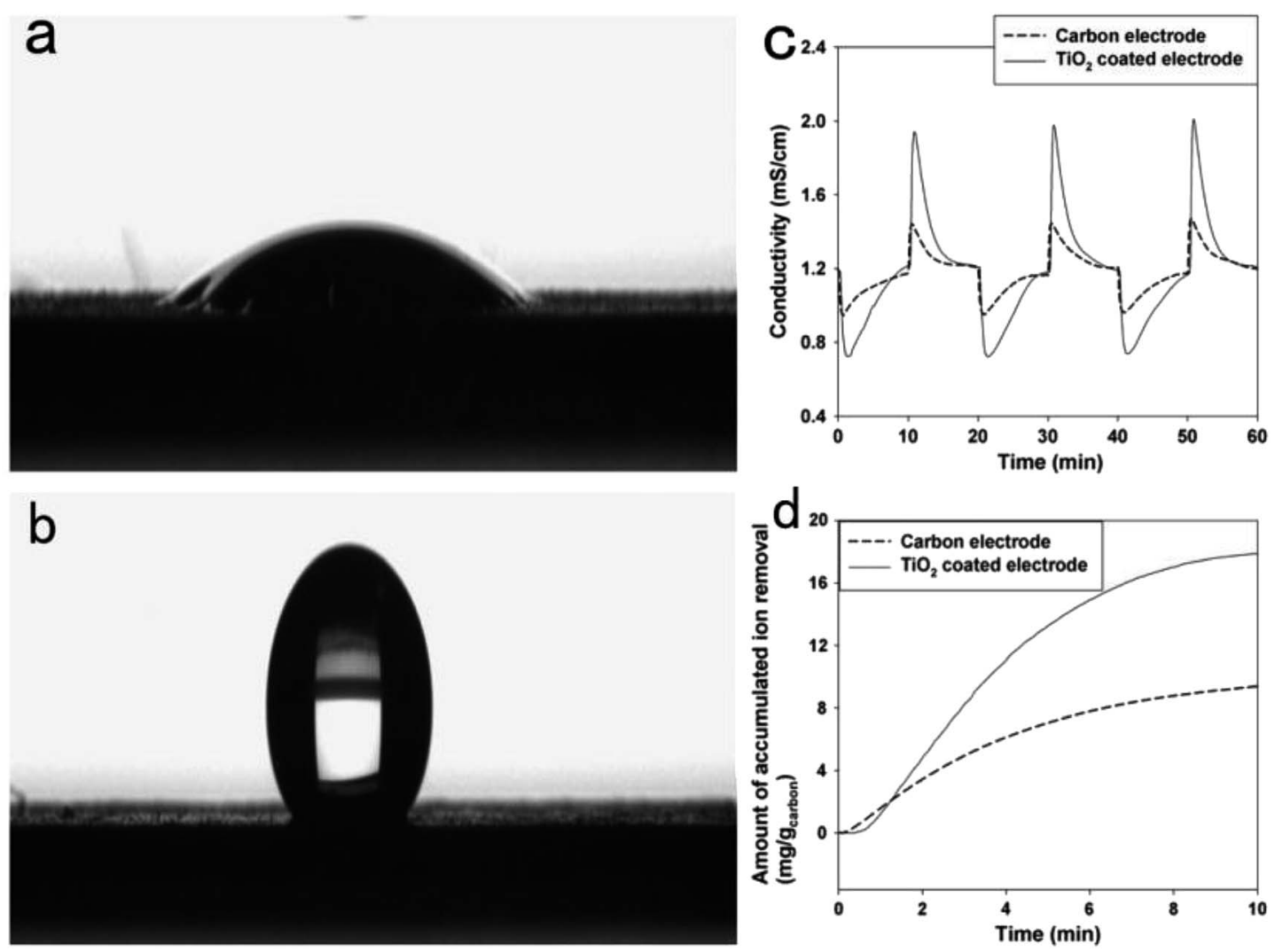

Fig. 4 Surface wetting property of (a) the $\mathrm{TiO}_{2}$ coated electrode and (b) carbon electrode. (c) lon removal performance. (d) Accumulated ion removal amount during the charging step (selected at the third cycle). Reproduced with permission from ref. 77.

vinylpyridine) coated activated carbon cathode in CDI, which led to a high SAC retention ratio of $95.4 \%$ after 350 adsorptiondesorption cycles, comparing with normal AC cathode in Fig. $5{ }^{87}$

Bryan et al. reported four tunnel crystal structures of manganese oxide nanowires as faradaic electrodes. ${ }^{88}$ Two of them are square tunnel structured $\mathrm{MnO}_{2}\left(\alpha-\mathrm{MnO}_{2}\right.$ and todorokite- $\mathrm{MnO}_{2}$ ), and others have ordered and disordered unions of structural tunnels, which had been shown in SEM and crosssectional HAADF-STEM images (Fig. 6). It was found that larger tunnels did a great favor to the removal of larger hydrated radii cations compared with the smaller ones. And the surface redox reactions as well as the intercalation of ions to the structural tunnels may be the main reason of ion removal.

In the study of Steven and Roland, ${ }^{89}$ electroless deposition (ED) and cyclic voltammetry (CV) were different methods to modify the electrodes and fabricated the $\mathrm{MnO}_{2}$ coated ones. Both techniques increased the electrode capacitance, however, only ED electrodes can improve the desalination performance. $\mathrm{MnO}_{2}$ mass deposition contributed dispersedly and fully in ED modified aerogel and while creating a discrete crust in CV electrodes. Thanks to this, a great specific charge capacitance $\left(77.6 \mathrm{~F} \mathrm{~g}^{-1}\right.$ ) was exhibited in a $\mathrm{MnO}_{2} / \mathrm{AC}$ composite electrode and storage capacity in thin-film sodium manganese oxide (NMO) was increased to 170 times higher than the uncoated electrodes. $^{90}$ And according to the report of Yang et al. ${ }^{91}$
Polystyrene Sodium Sulfonate (PSS) can facilitated the dispersion in composite electrodes and enhance the growth of $\mathrm{MnO}_{2}$, resulting in a great salt removal efficiency $(96.8 \%)$ and a high ion adsorption capacity $\left(80.4 \mu \mathrm{moL} \mathrm{g}^{-1}\right)$ in $\mathrm{MnO}_{2} / \mathrm{PSS} / \mathrm{CNTs}$ electrodes.

3.2.3. ZnO-modified carbon material. Zinc oxide $(\mathrm{ZnO})$ is an n-type broadband gap semiconductor and its unique properties enable it to grow in various forms on the surface of carbon materials. ${ }^{92,93}$ Myint et al. firstly applied ZnO nanomaterials to CDI technology and made continuous breakthroughs in this technology from 2012 to $2015 .{ }^{94-97}$ They focused on the application of zinc oxide nanocomposite electrodes grafted on activated carbon cloth in the removal of ions from brackish water by capacitive deionization. It was found that the polarization of $\mathrm{ZnO}$ nanorods increased the strength and penetration depth of electric field between the electrodes, thus improving the capacitance and charge efficiency to a certain extent. Besides, uniformly distributed electric field lines between two electrodes brought about faster ion adsorption rates as well as reduced electrode saturation time, resulting in $\sim 45 \%$ increase in the average desalination efficiency at all applied potentials.

Additionally, Liu et al. used polytetrafluoroethylene emulsion to mix AC particles and nano $\mathrm{ZnO}$ to prepare $\mathrm{ZnO} /$ $\mathrm{AC}$ composite electrodes. ${ }^{98}$ It was reported that $-\mathrm{ZnO} / \mathrm{AC} \| \mathrm{AC}$ capacitor showed a very stable CDI performance with significant electrosorption capacity of $9.4 \mathrm{mg} \mathrm{g}^{-1}$ and charge 

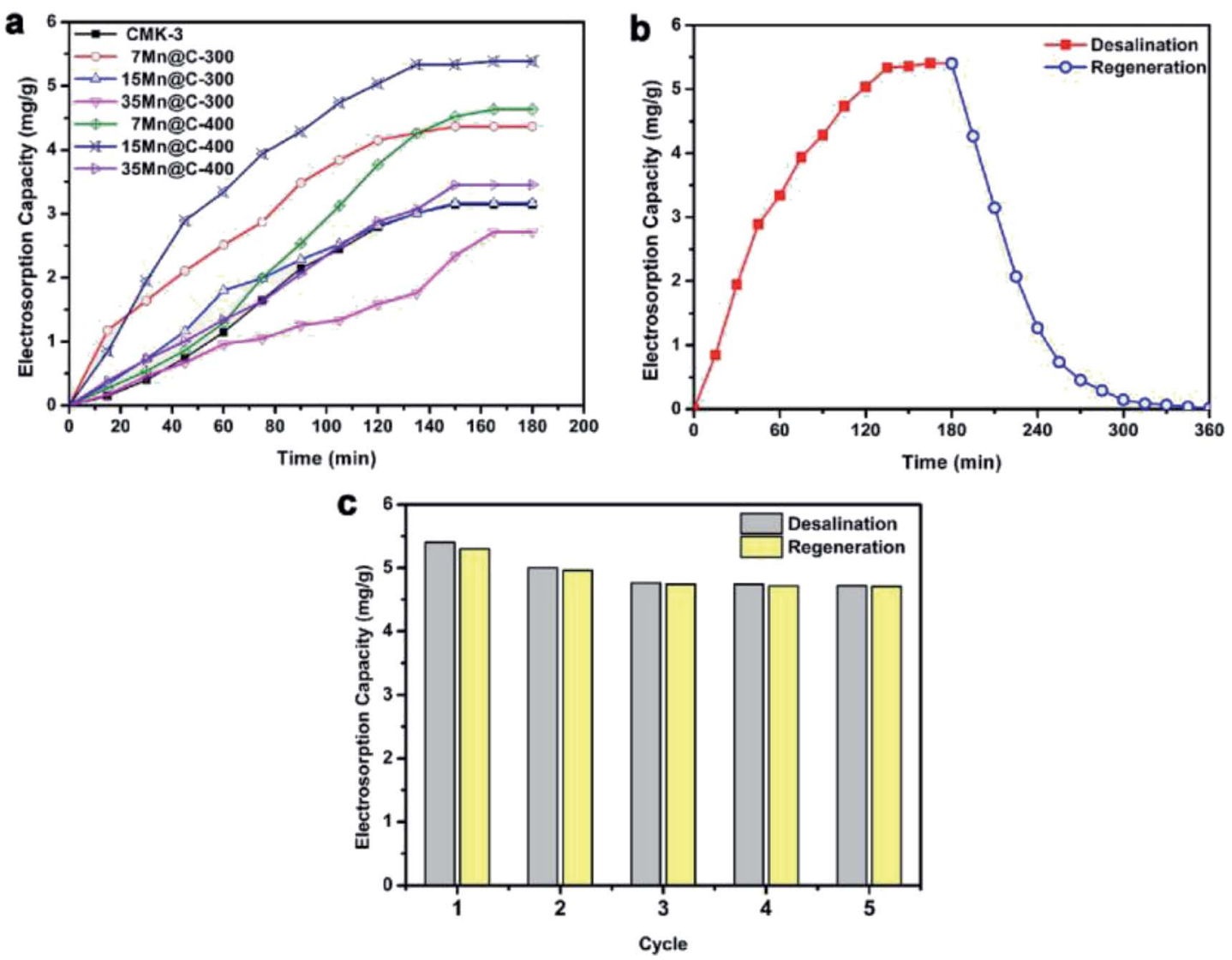

Fig. 5 (a) $\mathrm{CDI}$ profiles of $\mathrm{CMK}-3$ and $x \mathrm{MnCC}-\mathrm{T}$ hybrids under $1.2 \mathrm{~V}$; (b) deionization-regeneration profile and (c) deionization-regeneration cycles of the $15 \mathrm{MnaC}-400$ electrode. Reproduced with permission from ref. 87.

efficiency of $80.5 \%$, while $+\mathrm{ZnO} / \mathrm{AC} \| \mathrm{AC}$ capacitor showed declining desalination behavior after several chargedischarge cycles, as evident from Fig. 7. The different CDI properties on negative and positive electrodes were due to the changes of $\mathrm{pH}$ during charging process, which led to zeta potential variation of $\mathrm{ZnO}$.

3.2.4. Other metal oxide-modified carbon material. Wouters et al. ${ }^{99}$ synthesized carbon fiber sheets coated with thin-films of $\mathrm{SiO}_{2}$ and $\gamma-\mathrm{Al}_{2} \mathrm{O}_{3}$. It showed a desalination efficiency of $\mathrm{Ca}^{2+}$ greater than $90 \%$, which was $30 \%$ higher than that of uncoated carbon. This promotion could be attributed to the increase of specific surface area (SSA) and wettability of the composite, as well as the decrease of the resistance to ion transport process. It was also found that $\gamma-\mathrm{Al}_{2} \mathrm{O}_{3}$ exhibited a positive charge while $\mathrm{SiO}_{2}$ a negative charge. When applied potential had the same polarity as that of the coatings, the electrosorption capacity for counter-ions could get enhanced.

Additionally, Deen et al. ${ }^{100}$ reported graphene/tin dioxide nanoparticles composites $\left(\mathrm{Gr} / \mathrm{SnO}_{2}\right)$ fabricated by microwave irradiation. The incorporation of $\mathrm{SnO}_{2}$ led to a high specific capacitance of $323 \mathrm{~F} \mathrm{~g}^{-1}$, and prevented graphene sheets from aggregating, which brought about a significant increase in surface area. In CDI experiments, electrode with $15 \mathrm{wt} \% \mathrm{SnO}_{2}$ showed excellent cycling stability as well as considerable desalination efficiency of $83 \%$.
$\mathrm{Fe}_{3} \mathrm{O}_{4}$ is a chemically stable and environmentally friendly material, with high pseudocapacitance. $\mathrm{Fe}_{3} \mathrm{O}_{4} / \mathrm{RGO}$ nanocomposites synthesized via hydrothermal method were reported by Li et al. ${ }^{101}$ Cyclic voltammetry curve of this composite revealed a typical electrical double layer capacitive behavior and an enhanced specific capacitance, probably attributed to the surface hydroxylation of $\mathrm{Fe}_{3} \mathrm{O}_{4}$. The maximum electrosorption capacity of $\mathrm{Fe}_{3} \mathrm{O}_{4} / \mathrm{RGO}$ nanocomposites calculated by Langmuir model was $8.33 \mathrm{mg} \mathrm{g}^{-1}$, which was twice as high as that of RGO $\left(4.63 \mathrm{mg} \mathrm{g}^{-1}\right)$.

\subsection{Chemical treatment of carbon material}

3.3.1. Acid treatment. Generally, acid treatments are associated with surface oxidation of carbon materials, which lead to huge improvement in oxygen-containing functional surface groups, such as carboxyl, carbonyl, hydroxyl, quinone, lactone, etc. ${ }^{102}$ These functional groups are vital for the adsorption of alkaline-earth metals due to chelating effect. Besides, electrochemical properties and wettability of carbon materials will also benefit from these groups.

Acidic oxidizing agents such as concentrated nitric acid and concentrated sulfuric acid have been extensively used for the acid treatment of carbon materials. Huang et al. ${ }^{103}$ reported nitric acid-modified AC electrodes for capacitive deionization. 

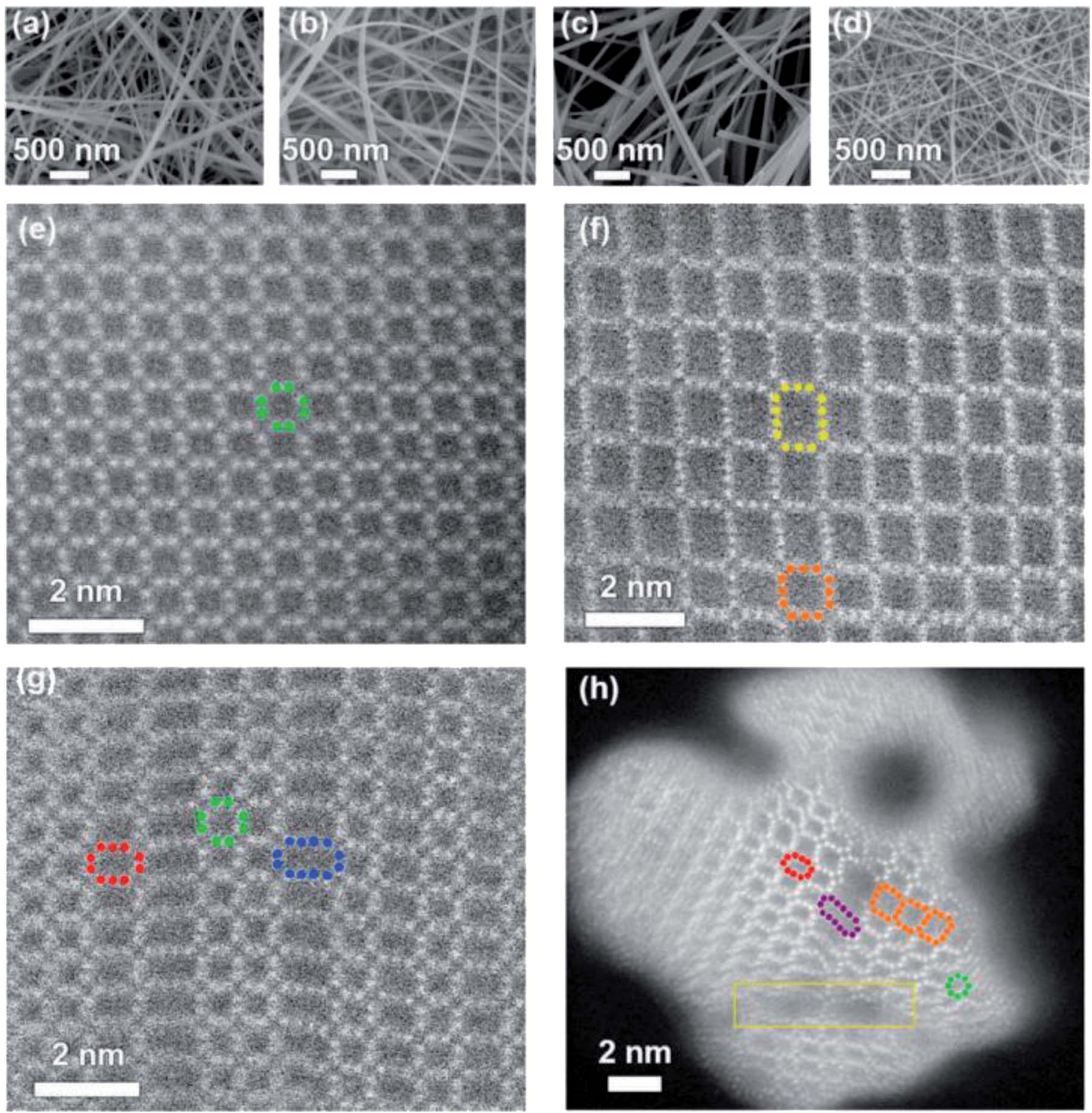

Fig. $6 \mathrm{SEM}(\mathrm{a}-\mathrm{d})$ and cross-sectional HAADF-STEM (e-h) images of $\alpha-\mathrm{MnO}_{2}$, Tod- $\mathrm{MnO}_{2}, 2 \times n-\mathrm{MnO}_{2}$, and hybrid- $\mathrm{MnO}_{2}$ : (a and e) $\alpha-\mathrm{MnO}$, (b and f) Tod $-\mathrm{MnO}_{2}$, (c and g) $2 \times n-\mathrm{MnO}_{2}$, and (d and h) hybrid $\mathrm{MnO}_{2}$. Reproduced with permission from ref. 88 .

Attributed to improved capacitance of AC caused by the increase of oxygen-containing functional surface groups, CDI experiments showed that desalination efficiency had increased by $15 \%$. To prepare sulfuric acid functionalized AC(FAC), Niu et al. ${ }^{104}$ modified activated carbon with $98 \%$ sulfuric acid via hydrothermal method. Compared to pure AC, FAC exhibited an improved electrosorption capacity of $3.54 \mathrm{mg} \mathrm{g}^{-1}$. Wu et al. ${ }^{105}$ treated activated carbon fiber with $6 \mathrm{M}$ nitric acid to reduce coion expulsion effect. Electrosorption capacity of this $\mathrm{ACF}-\mathrm{HNO}_{3}$ could reach up to $12.8 \mathrm{mg} \mathrm{g}^{-1}$. In this work, carboxylic groups were grafted onto the ACF surface, which positively shifted the potential of zero charge (Epzc) of ACF. It could be observed that ACF- $\mathrm{HNO}_{3}$ is unable to adsorb many anions even at a positive voltage, indicating its excellent cation selectivity. Thus, the coion expulsion effect which decreases adsorption capacity was limited.
Though traditional oxidation treatment of carbon materials can promote electrosorption capacity, it is destructive to the surface area and porous structure. In the research of MarotoValer et al. ${ }^{106}$ nitric acid treatment of activated carbon was reported to decrease the total pore volume and BET surface area by $8.8 \%$ and $9.2 \%$ respectively. A promising method to improve this status is oxygen plasma treatment, which can oxidize the carbon external surface without modifying the internal structure effectively. Talemi et al. ${ }^{\mathbf{1 0 7}}$ reported oxygen plasma modified carbon electrodes. In their study, electrosorption capacity was enhanced but there was no obvious specific surface area change. Also, the SEM images of electrodes at different levels of magnification shows no distinct variation on the surface after oxygen plasma treatment.

3.3.2. Alkali treatment. Alkali represented by potassium hydroxide usually has the function of chemical activation. As 

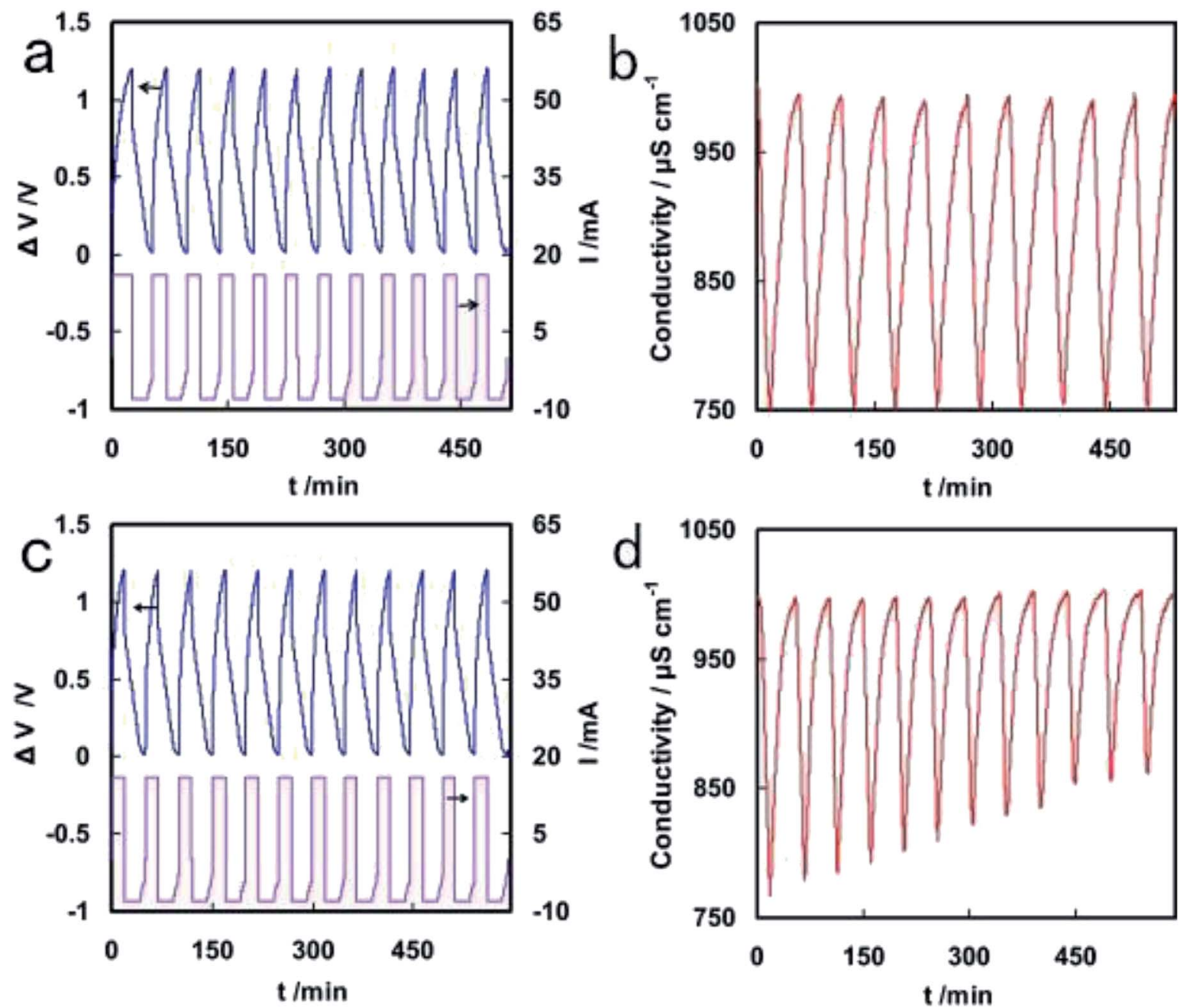

65
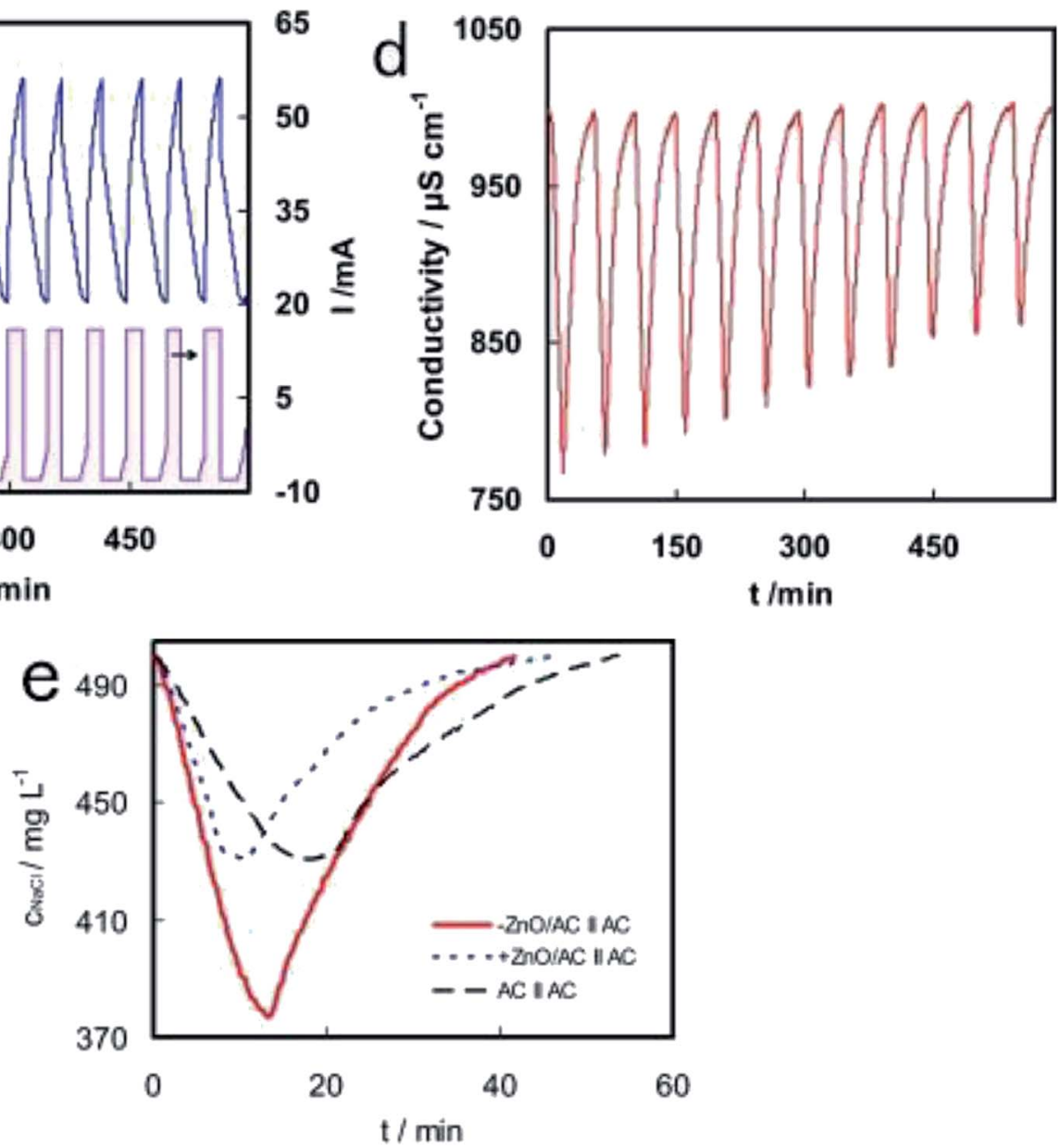

Fig. 7 Cell voltage/current curves ( $a$ and $c$ ) and conductivity variation ( $b$ and $d$ ) with time on $-\mathrm{ZnO} / \mathrm{AC} \| \mathrm{AC}(\mathrm{a}$ and $\mathrm{b}$ ) and $+\mathrm{ZnO} / \mathrm{AC} \| \mathrm{AC}$ (c and d) in the continuous charge-discharge process. (e) Conductivity variations of $-\mathrm{ZnO} / \mathrm{AC}\|\mathrm{AC},+\mathrm{ZnO} / \mathrm{AC}\| \mathrm{AC}$ and $\mathrm{AC} \| \mathrm{AC}$ in $C D I$ experiments. Reproduced with permission from ref. 98.

a highly efficient activator, potassium hydroxide has been widely used in the preparations of porous carbon materials with abundant pore structure and high specific surface area. Yeh et al. ${ }^{108}$ fabricated coconut shell-based activated carbons with various mesoporous ratio by manipulating the impregnation ratio of $\mathrm{KOH}$, which was shown in Fig. 8(a). From Fig. 8(b), it can be observed that in CDI experiments, the electrode with $70.7 \%$ ratio of mesoporosity (AC-1-2.0) showed a considerable electrosorption capacity of $9.72 \mathrm{mg}^{-1}$, higher than that of micropore-dominant electrodes, which indicated the association between mesoporosity ratio and electrosorption capacity. 
2
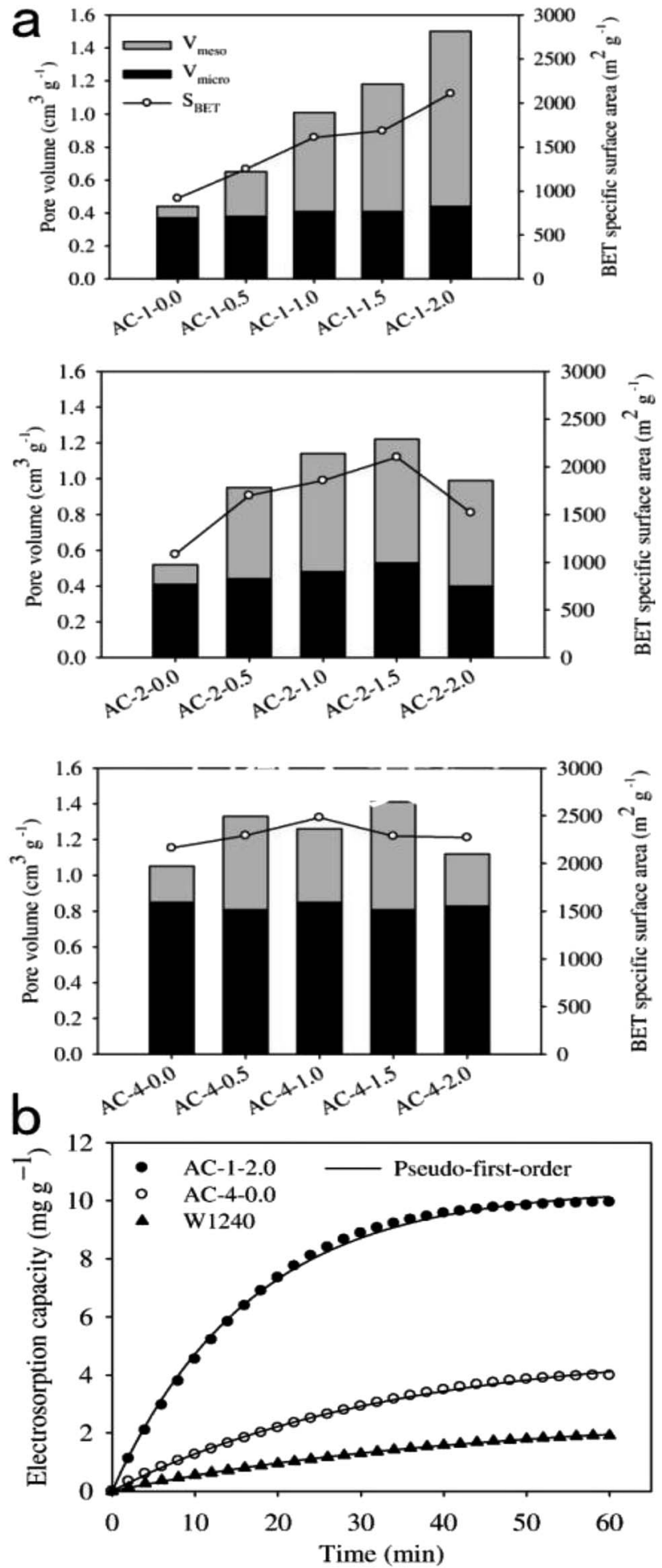

Fig. 8 (a) Pore characterization of the activated carbons prepared with different impregnation ratios of $\mathrm{KOH}$. (b) The electrosorption kinetics of AC-1-2.0, AC-4-0.0, and W1240 electrodes. Reproduced with permission from ref. 108 .

Dehkhoda et al. ${ }^{109}$ revealed a novel way to tailor porous activated biochar. By controlling drying conditions and carbonization temperature of $\mathrm{KOH}$ activation, biochars with predominantly mesoporous, microporous or combined porous structure could be obtained. Electrochemical analysis showed that electrodes with majorly microporous structure had high total capacitance $\left(222-245 \mathrm{~F} \mathrm{~g}^{-1}\right)$ but large electrode resistance, while mesopore-dominated electrodes $(>90 \%$ of total pore volume) possessed ideal capacitive behavior. CDI experiments suggest different ranges of desalination applications, with small hydrated ions $\left(\mathrm{Na}^{+}, \mathrm{K}^{+}, \mathrm{Cl}^{-}, \mathrm{Mg}^{2+}, \mathrm{Cu}^{2+}\right)$ utilizing microporous electrodes and larger ions $\left(\mathrm{Cr}^{3+}, \mathrm{Zn}^{2+}, \mathrm{Cd}^{3+}\right)$ utilizing mesoporous electrodes.

Besides optimizing pore structures, $\mathrm{KOH}$ also plays an important role in introducing hydrophilic functional groups. Ji et al. ${ }^{110}$ reported $\mathrm{KOH}$-modified activated carbons with higher surface area and increased surface hydrophilic functional groups, indicating the potential of $\mathrm{KOH}$ for improving wettability. Wang et al. ${ }^{111}$ modified activated carbon with different mass concentrations of KOH solution. The electrode modified with $5 \% \mathrm{KOH}$ exhibited a maximum specific capacitance of $108.8 \mathrm{~F} \mathrm{~g}^{-1}$ as well as $23 \%$ increase in desalination efficiency comparing to non-modified AC. The contact angle analysis and FTIR spectra image indicated that this promotion resulted from the introduction of hydroxyl functional groups on the electrode surface. Lee et al. ${ }^{112}$ studied the surface modification of carbon felts by $\mathrm{KOH}$ and $\mathrm{HNO}_{3}$. It was observed that $\mathrm{KOH}$ increased the BET surface area of the electrode, while $\mathrm{HNO}_{3}$ brought damages on the pore structure. Thus $\mathrm{KOH}$-modified carbon felts displayed higher desalination efficiency of $83.3 \%$ compared with $\mathrm{HNO}_{3}$-modified carbon felts $(65.4 \%)$, although the oxygencontaining functional groups formatted by $\mathrm{HNO}_{3}$ was much greater.

3.3.3. Other chemical treatment. As a hydrophilic group, sulfonic group $\left(-\mathrm{SO}_{3} \mathrm{H}\right)$ is expected to improve the wettability of carbon materials. In the work of Niu et al. ${ }^{104}$ mentioned above, the introduction of $-\mathrm{SO}_{3} \mathrm{H}$ was confirmed, which also resulted in the promotion of CDI performance. Qian et al. ${ }^{113}$ prepared sulfonated graphene (SG)-coated CNFs as MCDI electrodes. SG was abundant in negatively charged functional groups. By introducing it, CNFs were tuned from hydrophobic to hydrophilic. Thus in batch CDI experiments, this SG-CNF electrode exhibited an electrosorption capacity of $9.54 \mathrm{mg} \mathrm{g}^{-1}$ and increased by $22.0 \%$ in charge efficiency. Moreover, by introducing sulfonic groups, the co-ion repulsion effect can be reduced. Min et al. ${ }^{114}$ recently reported activated carbon materials modified by $\mathrm{TiO}_{2}$ coating and Tiron sulfonating (AC-Ti-S). The introduction of negatively charged sulfonic groups positively shifted the Epzc, as shown in Fig. 9. When AC-Ti-S was used as negative electrode, the co-ion repulsion effect could be reduced. Consequently, this AC-Ti-S electrode showed an electrosorption capacity of $7.6 \mathrm{mg} \mathrm{g}^{-1}$, which was 1.5 times as high as pristine AC.

Additionally, working voltage of CDI is dependent on the potential difference between the Epzc of cathode and anode. More negative Epzc of the cathode and more positive Epzc of the anode are required to enlarge the potential difference. Frequent oxygen-containing functional groups are negatively charged, which can positively shift the Epzc. Therefore, to further enlarge the potential difference, positively charged groups like $-\mathrm{NH}_{3}{ }^{+}$ are of great importance. Gao et al. ${ }^{59}$ synthesized amine-modified 

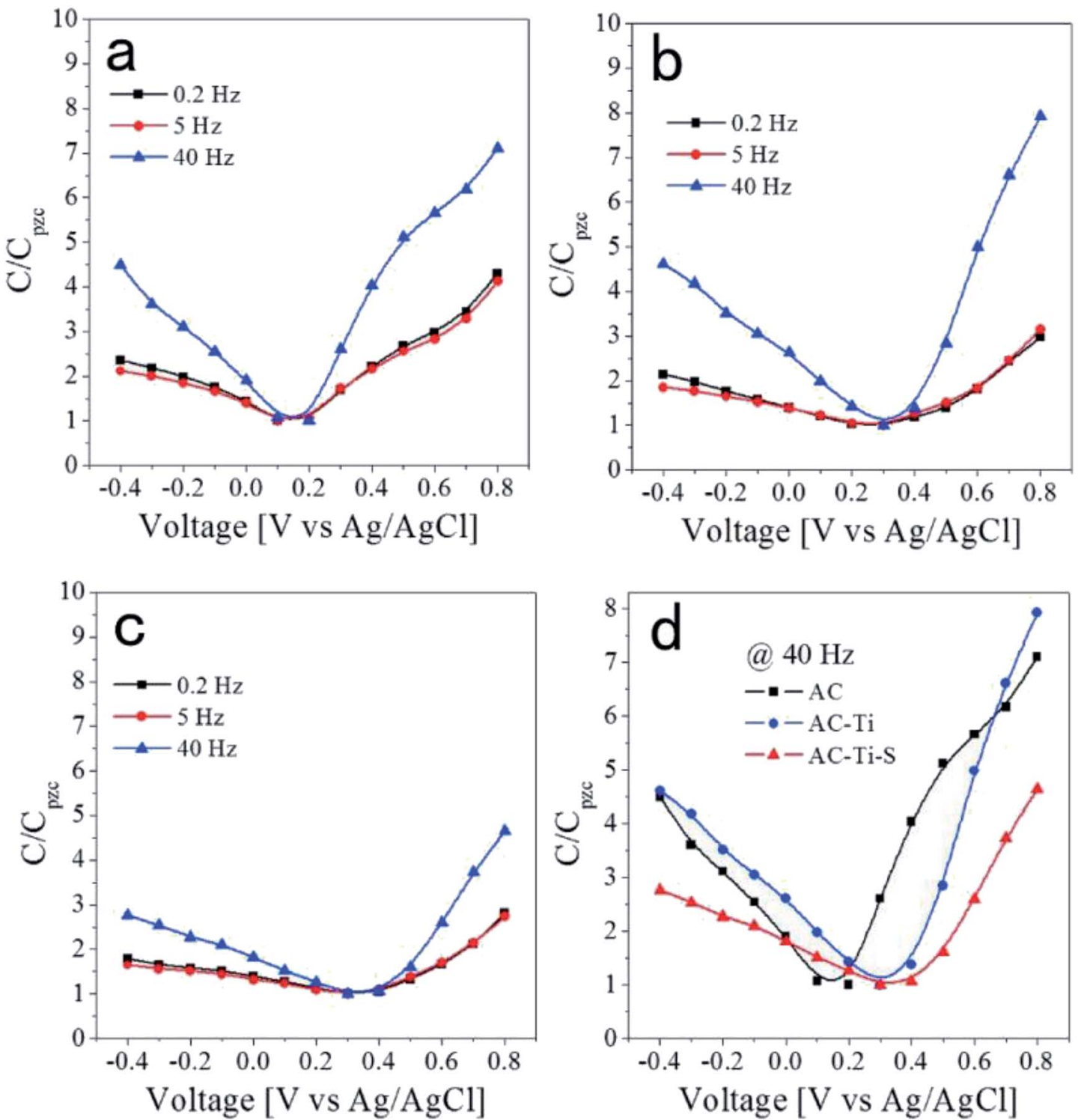

Fig. 9 Relative capacitance at various frequencies as a function of the applied voltage for the (a) AC, (b) AC-Ti and (c) AC-Ti-S electrodes. (d) The comparison of the C/CPZC values at $40 \mathrm{~Hz}$. Reproduced with permission from ref. 114.

microporous carbon cloths. To attach $-\mathrm{NH}_{2}$ functional groups onto the surface, nitric acid-treated carbon cloth was further modified by ethylenediamine. In neutral solution such as $\mathrm{NaCl}$, $-\mathrm{NH}_{2}$ was protonated to $-\mathrm{NH}_{3}{ }^{+}$, resulting in the increase of surface positive charges which led to promoted desalination capacity of $5.3 \mathrm{mg} \mathrm{g}^{-1}$. Additionally, ion selectivity of $-\mathrm{NH}_{3}{ }^{+}$was utilized to promote CDI performance, reported by Liu et al. ${ }^{115}$ They synthesized a novel 3D graphene electrode grafted with amine and sulfonic functional groups. Those charged groups could serve as ion-selective functional coatings to reduce the coion effect. As a consequence, this electrode displayed an excellent electrosorption capacity of $13.72 \mathrm{mg} \mathrm{g}^{-1}$ and a high charge efficiency of $85 \%$.

\subsection{Electrode coated in CDI}

Working voltage of CDI depends on the potential difference between the Epzc of cathode and anode. Cation-exchange polymer and metallic oxide account for a large part of materials used for coating the electrodes. The latter has been introduced in the above article, so we will focus on different cationexchange polymers coating on electrodes in this part.

The cation-exchange polymer coated electrode, widely used in membrane capacitive deionization (MCDI), is found more efficient than most of commercial carbon electrodes. ${ }^{\mathbf{1 1 6}}$ Among a large amount of efforts over the years to prolong the service life of a CDI device and decrease the interfacial resistance of the membrane capacitive deionization, coating layers of cationexchange polymer on the electrodes seems perfectly solving the problems. ${ }^{117}$

Kim and $\mathrm{Choi}^{\mathbf{1 1 8}}$ reported a method to fabricate polyvinyl alcohol (PVA) and sulfosuccinic acid (SSA) coated electrodes, which was considered as a milestone in the synthetize of a cation-exchange polymer coated electrode. The salt-removal efficiencies were observed to increase from $50-67 \%$ to $75-$ 
$85 \%$. The similar material, reported by Kim et al. ${ }^{119}$ was fabricated by blending PVA with SSA and poly(styrene sulfonic acidco-maleic acid) (PSSA_MA) (PVA/PSSA_MA/SSA), in which the removal efficiency of these electrodes were different due to disparate crosslinking synthesis temperatures and SSA contents. The PVA/SSA coating showed high adhesion to the electrodes, and the interfacial resistance of membrane capacitive deionization was much lower than the commercial ones, so the removal efficiency increased to $88 \%$ in a mixed solution with $300 \mathrm{ppm}$. According to the images of the surfaces and cross-sections of the electrode and ion exchange polymercoated electrodes, the carbon electrode surfaces were better coated with both cation and anion exchange polymers.

A new composite, reported by Yan et al., was fabricated in situ polymerization with polymer polyaniline and activated carbon. The combination of materials provided a considerable improvement of conductivity, in the meantime decreasing the number of micropores. And the promotion came from the conducting chains which linked microactivated carbon granules together and blocked a large amount of micropores.

Liu et al. reported m-MCDI electrodes fabricated by leading the anion exchange polymer (dimethyl diallyl ammonium chloride) and cation exchange (polyethyleneimine) polymer into CNT electrodes. What illustrated detailly in the article was that due to the reduction of co-ion expulsion effect while introducing ion exchange polymers and enhancing adhesion between ion exchange polymers and electrodes, it exhibited a relatively high $\mathrm{NaCl}$ removal of $93 \% .{ }^{\mathbf{1 2 0}}$ And the "co-in" effect could also be reduced by coating the sulfonated poly(phenylene oxide) and aminated polysulfone on the surface of traditional carbon electrodes.

With a new electrode, a salt removal efficiency of nearly $100 \%$ was obtained, which was illustrated. This electrode was fabricated with synthesized sulfonated poly(phenylene oxide) (SPPO) and aminated polysulfone (APSf), which realized a leap of the performance of membrane capacitive deionization (MCDI). Thanks to its coatings of sufficient thickness at $4.89 \mu \mathrm{m}$ for SPPO and $5.16 \mu \mathrm{m}$ for APSf, adequate anchoring of the polymers made sure there wasn't any delamination. ${ }^{\mathbf{1 2 1}}$

Moreover, the ratio of selectivity to the degree of resistance enhancement was found to have positive correlation with the degree of promotion in MCDI performance. ${ }^{122}$ The negative electrode was coated with Ca-alginate in MCDI for hardness control and showed great ion removal efficient for hardness species like calcium ions, which were $44 \%$ more than that of the commercial CDI, as shown in Fig. 10.

In recent years, CNTs has been widely used in electrode coated for its special property. Wang et al. synthetized carbon nanotube and polypyrrole (PPy) composite electrode with the method of chemical oxidation and used sodium dodecyl benzene sulfonate as the dopant. Their experiment showed the PPy/CNT composites enhanced the capacitance of electrodes three times than traditional carbon nanotubes and considerably improved their adsorption capacity. Compared to CNT, the TEM image of PPy/CNT composites indicated that PPy/CNT composites were nanotube form with the CNT wrapped by the uniform PPy layer, as shown in Fig. $11 .{ }^{123}$ Mechanism of the PPy/

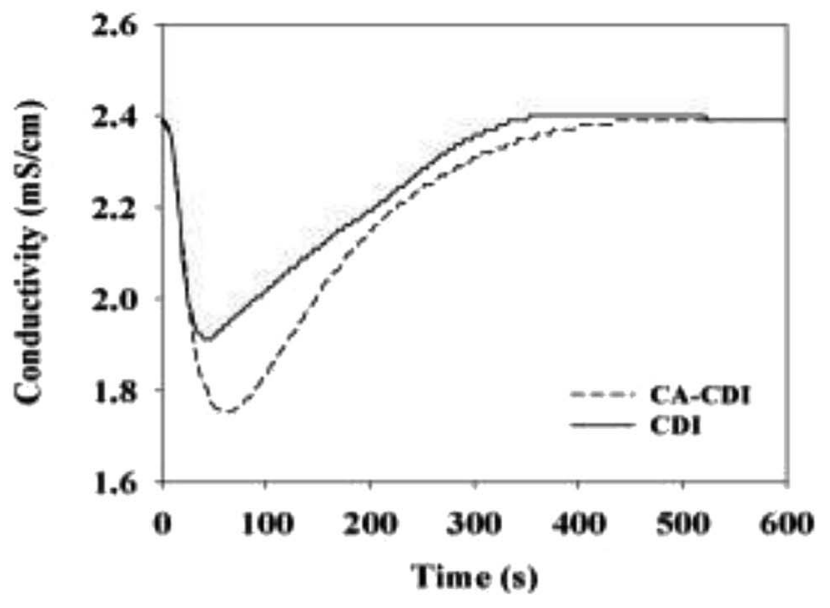

(a)

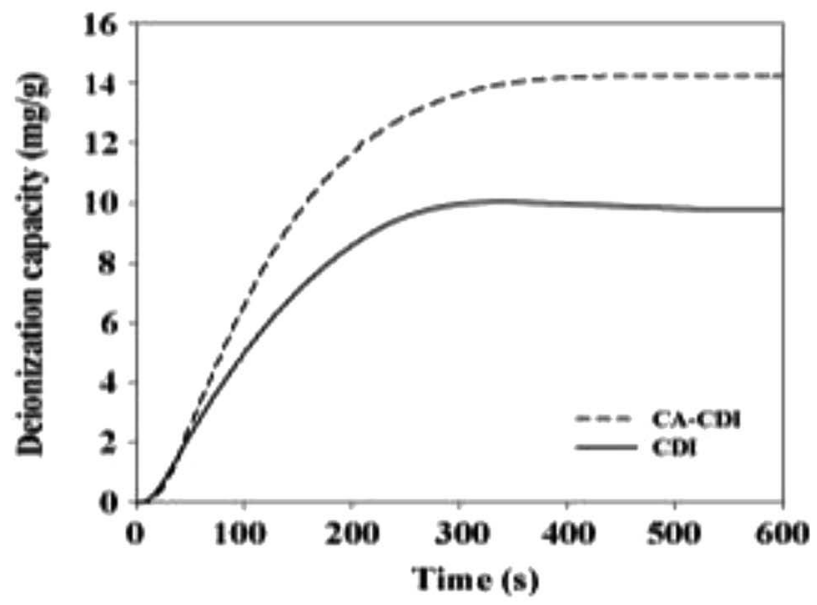

(b)

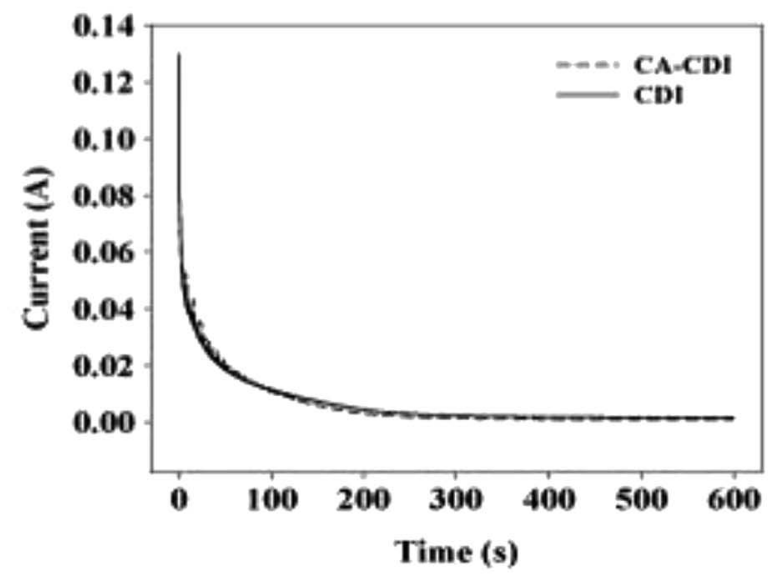

(c)

Fig. 10 (a) Conductivity profile, (b) deionization capacity and (c) consumed current of $\mathrm{Ca}$-alginate coated CDI (CA-CDI) compared with the control CDI with time. Reproduced with permission from ref. 122.

CNT's satisfying performance was that the uniform and loose PPy layer resulted in the lower charging resistance of the coated electrode than that of commercial CNTs. ${ }^{\mathbf{1 2 4}}$

Besides the cation-exchange polymer coated electrodes, electrodes coated with other materials were also studied by 

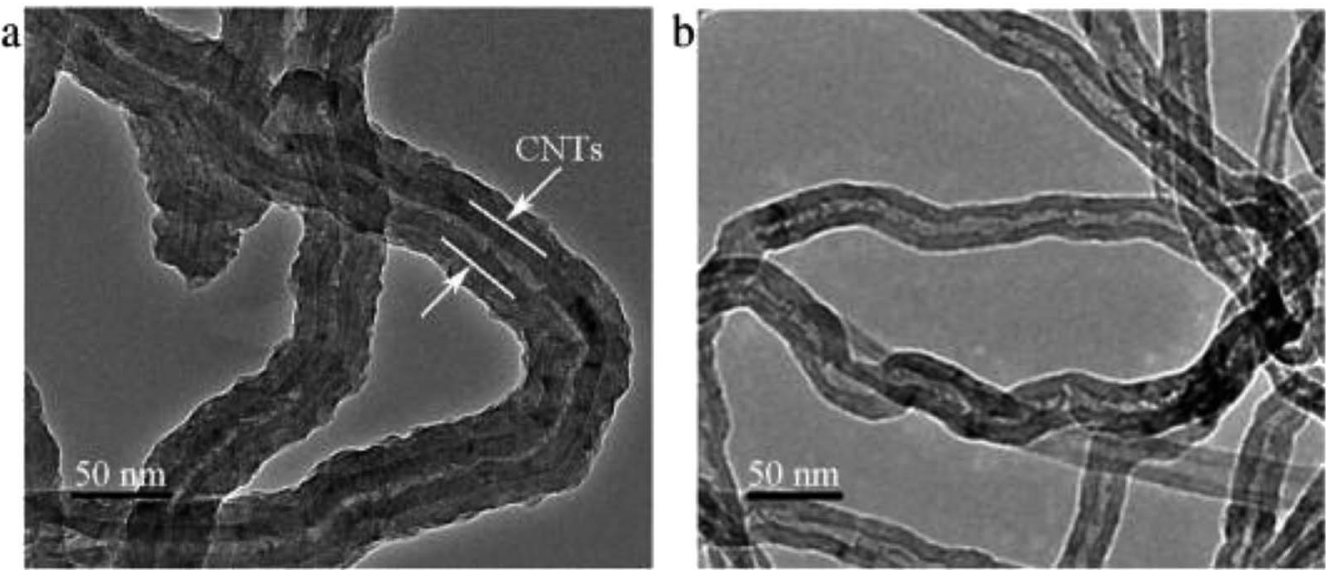

Fig. 11 SEM images of (a) PPy/CNT composites and (b) CNT. Reproduced with permission from ref. 123.

many researchers. Yoon et al. tested the Ag coated hybrid CDI system. ${ }^{125}$ The enhanced specific capacity uniting the capacitance in $\mathrm{AC}$ electrode with the $\mathrm{Ag}$ mediated charge transfer reaction, leading to a significant improvement - the charge efficiency (116\%), the CDI deionization capacity $(188 \%)$ and rate $(139 \%)$.

\section{Summary}

As a novel water treatment technology, capacitive deionization has drawn wide attention for the advantages of lower energy consumption and cost, higher efficiency and better regeneration. Selection and modification of electrode materials is one of the most essential factors affecting desalination performance, which has become the focus of CDI research in recent years. In this article, we summarize the modification methods of carbon materials including heteroatom doping, metal oxide modification, chemical treatment and surface coating, and analyze their mechanism for enhancing CDI performance. The electrochemical and electrosorption performances of various carbon electrodes modified by different methods are summarized in Table 2.

Generally speaking, the purpose of modification is to improve the properties of carbon electrodes, such as the porous structure, specific surface area, wettability and conductivity. Specifically, element doping is mainly used to optimize the pore structure and increase the specific surface area of the carbon materials. Nitrogen doping can also introduce nitrogencontaining functional groups to enhance hydrophilicity and conductivity. Metal oxide modification, represented by $\mathrm{TiO}_{2}$, can considerably improve the wettability of carbon electrode by introducing hydroxyl groups on the surface. Additionally, the combination of carbon and metal oxides is able to increase the specific capacitance for the reason of synergistic effects. Acid treatment generally leads to significant increase in oxygencontaining functional surface groups. Apart from improving wettability and hydrophilicity, these negatively charged functional groups can positively shift the Epzc of carbon materials, thus reducing the co-ion expulsion effect and promoting electrosorption capacity. Alkali treatment is used to tailor porous carbon materials with different ratios of mesoporosity, due to the chemical activation function of alkali. Besides, cation-exchange polymer coating layers can reduce the interfacial resistance of MCDI which leads to the enhancement of electrochemical performance.

Although these methods can lead to an increase in CDI performance, there still exist some shortcomings. Element doping usually needs high temperature, but the specific temperatures are unpredictable thus requiring large numbers of experiment. In addition, acid treatment is destructive to the surface area and porous structure of carbon electrode due to the oxidation process. Talemi et al. proposed a solution of oxygen plasma modification, but the complicated operations limited its further promotion. ${ }^{107}$ Moreover, the introduction of surface functional groups can accelerate the faradaic reactions which reduce the charging efficiency. By taking such issues, CDI performance will be further improved.

\section{Prospects}

As a new type of desalination technology developed rapidly in the middle and late 19th century, CDI has attracted the attention of scholars with its high economical value and perfect stability. However, there are still several aspects that limit the development of CDI in practical applications. The biggest problem remains that the electrosorption performance of conventional electrode materials limits the upper limit of CDI material adsorption. High specific area materials such as activated carbon, graphene, and carbon aerogel have good pore structure and electrochemical properties, but for decades, the space for increasing the unit adsorption capacity is still very limited. This is the basic reason for various modification methods proposed to increase the unit adsorption amount. In fact, in addition to the various modification methods discussed in this paper, there is another new idea that can effectively improve the adsorption efficiency of CDI units. That is to replace the traditional electrosorption theory with a reversible chemical reaction. This theory is based on the fact that the 
Table 2 Different carbon electrodes and their CDI performances

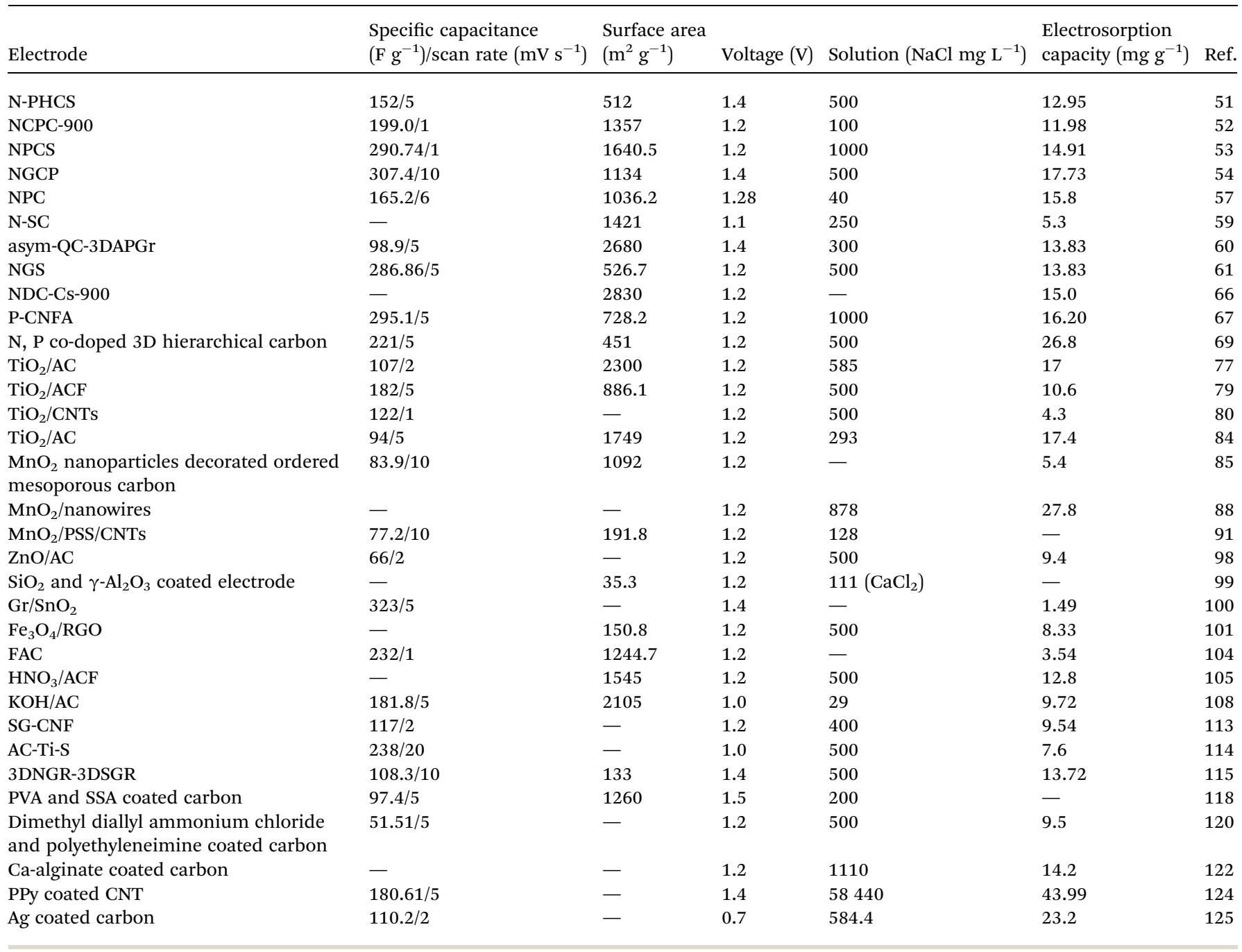

Faraday capacitance is much larger than the double layer capacity of the material. Tantalum capacitance refers to the underpotential deposition of electroactive materials in the twodimensional or quasi-two-dimensional space on the surface or in the bulk phase, resulting in highly reversible chemisorption, desorption or redox reactions, which are related to the charge potential of the electrode capacitance. It can be produced not only on the surface of the electrode but also inside the entire electrode, so its development potential is enormous. For example, a Prussian blue analogue has recently been proposed as an electrode material for high-efficiency capacitive deionization. Its unique open-frame structure of large ion channels makes it an excellent material for $\mathrm{Na}^{+}$intercalation and deintercalation. It is reported that the unit adsorption capacity can be up to $59.9 \mathrm{mg} \mathrm{g}^{-1}$, this result is difficult to achieve with traditional carbon-based materials, and it indicates that this may be the key to CDI's future use in actual water desalination.

Another major factor limiting CDI to the theoretical level is the general adsorption of various types of ions. The simple electrochemical principle of CDI indicates that the highly charged ions with appropriate pore size are more easily absorbed, and the low-charge materials whose pore size does not conform to the pore structure of the material are not easily absorbed. In other words, the selective adsorption capacity of CDI is weak. This is also a major technical vacancy in the field of CDI. Specific adsorption is of great significance for the recycling of various ions and the enrichment of heavy metals. Related studies have shown that from the perspective of pore structure, the unit adsorption capacity of traditional carbon-based materials can be effectively improved, while positive and negative charge modification can achieve the effect of ion selection to some extent. Once a breakthrough is made, it will definitely be a major advancement in the application of CDI to actual water treatment.

In conclusion, capacitive deionization is a promising technology. Through continuous research, CDI will play an important role in sewage disposal and seawater desalination in the future.

\section{Conflicts of interest}

There are no conflicts to declare. 


\section{Acknowledgements}

This work was supported by the National College Students' Innovation and Entrepreneurship Training Program (No. 201810055107) and National Key R\&D Program of China (No. 2016YFC 0400704).

\section{References}

1 Z. Amor, B. Bariou, N. Mameri, M. Taky, S. Nicolas and A. Elmidaoui, Desalination, 2001, 133, 215-223.

2 Y. Tokui, H. Moriguchi and Y. Nishi, Desalination, 2014, 351, 145-150.

3 K. P. Lee, T. C. Arnot and D. Mattia,J. Membr. Sci., 2011, 370, 1-22.

4 H. Sayyaadi and A. Saffari, Appl. Energy, 2010, 87, 11221133.

5 X. X. Cao, X. Huang, P. Liang, K. Xiao, Y. J. Zhou, X. Y. Zhang and B. E. Logan, Environ. Sci. Technol., 2009, 43, 7148-7152.

6 S. J. Kim, S. H. Ko, K. H. Kang and J. Han, Nat. Nanotechnol., 2010, 5, 297-301.

7 T. J. Welgemoed and C. F. Schutte, Desalination, 2005, 183, 327-340.

8 S. Porada, R. Zhao, A. van der Wal, V. Presser and P. M. Biesheuvel, Prog. Mater. Sci., 2013, 58, 1388-1442.

9 H. B. Li, L. Zou, L. K. Pan and Z. Sun, Sep. Purif. Technol., 2010, 75, 8-14.

10 S. J. Seo, H. Jeon, J. K. Lee, G. Y. Kim, D. Park, H. Nojima, J. Lee and S. H. Moon, Water Res., 2010, 44, 2267-2275.

11 F. A. AlMarzooqi, A. A. Al Ghaferi, I. Saadat and N. Hilal, Desalination, 2014, 342, 3-15.

12 S. M. Jung, J. H. Choi and J. H. Kim, Sep. Purif. Technol., 2012, 98, 31-35.

13 R. Zhao, P. M. Biesheuvel, H. Miedema, H. Bruning and A. van der Wal, J. Phys. Chem. Lett., 2010, 1, 205-210.

14 L. L. Yuan, X. F. Yang, P. Liang, L. Wang, Z. H. Huang, J. C. Wei and X. Huang, Bioresour. Technol., 2012, 110, 735-738.

15 C. J. Feng, C. H. Hou, S. H. Chen and C. P. Yu, Chemosphere, 2013, 91, 623-628.

16 M. W. Ryoo and G. Seo, Water Res., 2003, 37, 1527-1534.

17 H. J. Oh, J. H. Lee, H. J. Ahn, Y. Jeong, Y. J. Kim and C. S. Chi, Thin Solid Films, 2006, 515, 220-225.

18 G. Wang, B. Q. Qian, Q. Dong, J. Y. Yang, Z. B. Zhao and J. S. Qiu, Sep. Purif. Technol., 2013, 103, 216-221.

19 G. X. Zhao, J. X. Li, X. M. Ren, C. L. Chen and X. K. Wang, Environ. Sci. Technol., 2011, 45, 10454-10462.

20 Z. Peng, D. S. Zhang, L. Y. Shi and T. T. Yan, J. Mater. Chem., 2012, 22, 6603-6612.

21 H. Wang, L. Y. Shi, T. T. Yan, J. P. Zhang, Q. D. Zhong and D. S. Zhang, J. Mater. Chem. A, 2014, 2, 4739-4750.

22 P. Xu, J. E. Drewes, D. Heil and G. Wang, Water Res., 2008, 42, 2605-2617.

23 H. H. Jung, S. W. Hwang, S. H. Hyun, L. Kang-Ho and G. T. Kim, Desalination, 2007, 216, 377-385.
24 L. Wang, M. Wang, Z. H. Huang, T. X. Cui, X. C. Gui, F. Y. Kang, K. L. Wang and D. H. Wu, J. Mater. Chem., 2011, 21, 18295-18299.

25 C. J. Yan, L. Zou and R. Short, Desalination, 2012, 290, 125129.

26 C. Y. Nie, L. K. Pan, H. B. Li, T. Q. Chen, T. Lu and Z. Sun, J. Electroanal. Chem., 2012, 666, 85-88.

27 H. B. Li, L. D. Zou, L. K. Pan and Z. Sun, Environ. Sci. Technol., 2010, 44, 8692-8697.

28 H. B. Li, L. K. Pan, T. Lu, Y. K. Zhan, C. Y. Nie and Z. Sun, J. Electroanal. Chem., 2011, 653, 40-44.

29 Y. Liu, C. Y. Nie, X. J. Liu, X. T. Xu, Z. Sun and L. K. Pan, RSC $A d v .$, 2015, 5, 15205-15225.

30 J. Oladunni, J. H. Zain, A. Hai, F. Banat, G. Bharath and E. Alhseinat, Sep. Purif. Technol., 2018, 207, 291-320.

31 P. Y. Liu, T. T. Yan, L. Y. Shi, H. S. Park, X. C. Chen, Z. G. Zhao and D. S. Zhang, J. Mater. Chem. A, 2017, 5, 13907-13943.

32 B. P. Jia and W. Zhang, Nanoscale Res. Lett., 2016, 11, 64.

33 P. J. Lu, H. C. Lin, W. T. Yu and J. M. Chern, J. Taiwan Inst. Chem. Eng., 2011, 42, 305-311.

34 K. Y. Foo and B. H. Hameed, J. Hazard. Mater., 2009, 170, 552-559.

35 C. H. Hou, J. F. Huang, H. R. Lin and B. Y. Wang, J. Taiwan Inst. Chem. Eng., 2012, 43, 473-479.

36 K. K. Park, J. B. Lee, P. Y. Park, S. W. Yoon, J. S. Moon, H. M. Eum and C. W. Lee, Desalination, 2007, 206, 86-91.

37 B. H. Kim, K. S. Yang, Y. A. Kim, Y. J. Kim, B. An and K. Oshida, J. Power Sources, 2011, 196, 10496-10501.

38 Y. Z. Chen, M. B. Yue, Z. H. Huang and F. Y. Kang, Chem. Eng. J., 2014, 252, 30-37.

39 S. S. Wang, Y. L. Xu, M. F. Yan, Z. Z. Zhai, B. Ren, L. H. Zhang and Z. F. Liu, J. Electroanal. Chem., 2018, 809, 111-116.

40 D. S. Zhang, L. Y. Shi, J. H. Fang, K. Dai and X. K. Li, Mater. Chem. Phys., 2006, 97, 415-419.

41 K. Dai, L. Y. Shi, J. H. Fang, D. S. Zhang and B. K. Yu, Mater. Lett., 2005, 59, 1989-1992.

42 A. H. Jadhav, X. T. Mai, F. A. Ofori and H. Kim, Chem. Eng. J., 2015, 259, 348-356.

43 Y. Bai, Z. H. Huang, X. L. Yu and F. Y. Kang, Colloids Surf., A, 2014, 444, 153-158.

44 L. D. Zou, L. X. Li, H. H. Song and G. Morris, Water Res., 2008, 42, 2340-2348.

45 L. X. Li, L. D. Zou, H. H. Song and G. Morris, Carbon, 2009, 47, 775-781.

46 J. N. Coleman, Adv. Funct. Mater., 2009, 19, 3680-3695.

47 K. A. Kurak and A. B. Anderson, J. Phys. Chem. C, 2009, 113, 6730-6734.

48 Y. Zheng, Y. Jiao, J. Chen, J. Liu, J. Liang, A. Du, W. M. Zhang, Z. H. Zhu, S. C. Smith, M. Jaroniec, G. Q. Lu and S. Z. Qiao, J. Am. Chem. Soc., 2011, 133, 20116-20119.

49 M. Sevilla, P. Valle-Vigon and A. B. Fuertes, Adv. Funct. Mater., 2011, 21, 2781-2787.

50 N. Alam and R. Mokaya, Energy Environ. Sci., 2010, 3, 17731781. 
51 S. S. Zhao, T. T. Yan, H. Wang, G. R. Chen, L. Huang, J. P. Zhang, L. Y. Shi and D. S. Zhang, Appl. Surf. Sci., 2016, 369, 460-469.

52 Y. Li, Y. X. Liu, J. M. Shen, J. W. Qi, J. S. Li, X. Y. Sun, J. Y. Shen, W. Q. Han and L. J. Wang, Desalination, 2018, 430, 45-55.

53 Y. Liu, T. Q. Chen, T. Lu, Z. Sun, D. H. C. Chua and L. K. Pan, Electrochim. Acta, 2015, 158, 403-409.

54 T. Gao, Y. J. Du and H. B. Li, Sep. Purif. Technol., 2019, 211, 233-241.

55 X. Y. Duan, W. Liu and L. M. Chang, J. Taiwan Inst. Chem. Eng., 2016, 62, 132-139.

56 N. L. Liu, S. Dutta, R. R. Salunkhe, T. Ahamad, S. M. Alshehri, Y. Yamauchi, C. H. Hou and K. C. W. Wu, Sci. Rep., 2016, 6, 28847.

57 C. J. Zhao, G. Q. Liu, N. Sun, X. Zhang, G. Z. Wang, Y. X. Zhang, H. M. Zhang and H. J. Zhao, Chem. Eng. J., 2018, 334, 1270-1280.

58 J. Yang, L. D. Zou and N. R. Choudhury, Electrochim. Acta, 2013, 91, 11-19.

59 X. Gao, A. Omosebi, J. Landon and K. L. Liu, Environ. Sci. Technol., 2015, 49, 10920-10926.

60 A. G. El-Deen, R. M. Boom, H. Y. Kim, H. W. Duan, M. B. Chan-Park and J. H. Choi, ACS Appl. Mater. Interfaces, 2016, 8, 25313-25325.

61 X. T. Xu, Z. Sun, D. H. C. Chua and L. K. Pan, Sci. Rep., 2015, 5, 8458.

62 A. Amiri, G. Ahmadi, M. Shanbedi, M. Savari, S. N. Kazi and B. T. Chew, Sci. Rep., 2015, 5, 17503.

63 L. J. Liu, X. R. Guo, R. Tallon, X. K. Huang and J. H. Chen, Chem. Commun., 2017, 53, 881-884.

64 M. Zhou, F. Pu, H. Chen, Z. Wang, H. Y. Zhang and S. Y. Guan, New J. Chem., 2013, 37, 4148-4155.

65 X. L. Ma, X. Y. Song, G. Q. Ning, L. Q. Hou, Y. F. Kan, Z. H. Xiao, W. Li, G. X. Ma, J. S. Gao and Y. F. Li, Ind. Eng. Chem. Res., 2017, 56, 9524-9532.

66 S. Porada, F. Schipper, M. Aslan, M. Antonietti, V. Presser and T. P. Fellinger, Chemsuschem, 2015, 8, 1867-1874.

67 Y. J. Li, Y. Liu, M. Wang, X. T. Xu, T. Lu, C. Q. Sun and L. K. Pan, Carbon, 2018, 130, 377-383.

68 C. Li, Q. Fu, K. J. Zhao, Y. P. Wang, H. Tang, H. H. Li, H. B. Jiang and L. Chen, Carbon, 2018, 139, 1117-1125.

69 J. L. Han, L. Y. Shi, T. T. Yan, J. P. Zhang and D. S. Zhang, Environ. Sci.: Nano, 2018, 5, 2337-2345.

70 J. Zhang, J. H. Fang, J. L. Han, T. T. Yan, L. Y. Shi and D. S. Zhang, J. Mater. Chem. A, 2018, 6, 15245-15252.

71 T. Zhang, H. Zhao, X. X. Huang and G. Wen, Desalination, 2016, 379, 118-125.

72 Z. Q. Wang, Y. Wang, D. Y. Ma, S. C. Xu and J. X. Wang, Sep. Purif. Technol., 2018, 192, 15-20.

73 D. Y. Ma, Y. Wang, X. Y. Han, S. C. Xu and J. X. Wang, Sep. Purif. Technol., 2018, 201, 167-178.

74 Y. M. Cai, Y. Wang, X. Y. Han, L. W. Zhang, S. C. Xu and J. X. Wang, J. Electroanal. Chem., 2016, 768, 72-80.

75 Y. P. Zhang, X. W. Sun, L. K. Pan, H. B. Li, Z. Sun, C. P. Sun and B. K. Tay, Solid State Ionics, 2009, 180, 1525-1528.
76 M. W. Ryoo, J. H. Kim and G. Seo, J. Colloid Interface Sci., 2003, 264, 414-419.

77 C. Kim, J. Lee, S. Kim and J. Yoon, Desalination, 2014, 342, 70-74.

78 L. M. Chang, X. Y. Duan and W. Liu, Desalination, 2011, 270, 285-290.

79 D. H. Kang, H. Jo, M. J. Jung, K. L. Kim and Y. S. Lee, Carbon Letters, 2018, 27, 64-71.

80 H. B. Li, Y. L. Ma and R. Niu, Sep. Purif. Technol., 2016, 171, 93-100.

81 J. H. Feng, S. Xiong and Y. Wang, Sep. Purif. Technol., 2019, 213, 70-77.

82 I. Cohen, E. Avraham, Y. Bouhadana, A. Soffer and D. Aurbach, Electrochim. Acta, 2013, 106, 91-100.

83 P. Srimuk, L. Ries, M. Zeiger, S. Fleischmann, N. Jackel, A. Tolosa, B. Kruner, M. Aslan and V. Presser, $R S C A d v$., 2016, 6, 106081-106089.

84 P. Srimuk, M. Zeiger, N. Jackel, A. Tolosa, B. Kruner, S. Fleischmann, I. Grobelsek, M. Aslan, B. Shvartsev, M. E. Suss and V. Presser, Electrochim. Acta, 2017, 224, 314-328.

85 C. X. Zhao, X. Y. Lv, J. S. Li, T. Xie, Y. Y. Qi and W. Chen, J. Electrochem. Soc., 2017, 164, E505-E511.

86 J. Yang, L. D. Zou, H. H. Song and Z. P. Hao, Desalination, 2011, 276, 199-206.

87 T. T. Wu, G. Wang, S. Y. Wang, F. Zhan, Y. Fu, H. Y. Qiao and J. S. Qiu, Environ. Sci. Technol. Lett., 2018, 5, 98-102.

88 B. W. Byles, D. A. Cullen, K. L. More and E. Pomerantseva, Nano Energy, 2018, 44, 476-488.

89 S. Hand and R. D. Cusick, Environ. Sci. Technol., 2017, 51, 12027-12034.

90 J. M. Wallas, M. J. Young, H. X. Sun and S. M. George, J. Electrochem. Soc., 2018, 165, A2330-A2339.

91 J. Yang, L. D. Zou and H. H. Song, Desalination, 2012, 286, 108-114.

92 L. Schmidt-Mende and J. L. MacManus-Driscoll, Mater. Today, 2007, 10, 40-48.

93 S. Baruah and J. Dutta, Sci. Technol. Adv. Mater., 2009, 013001.

94 M. T. Z. Myint, S. H. Al-Harthi and J. Dutta, Desalination, 2014, 344, 236-242.

95 K. Laxman, M. T. Z. Myint, R. Khan, T. Pervez and J. Dutta, Desalination, 2015, 359, 64-70.

96 M. T. Z. Myint and J. Dutta, Desalination, 2012, 305, 24-30. 97 K. Laxman, M. T. Z. Myint, H. Bourdoucen and J. Dutta, ACS Appl. Mater. Interfaces, 2014, 6, 10113-10120.

98 J. Y. Liu, M. Lu, J. M. Yang, J. Cheng and W. S. Cai, Electrochim. Acta, 2015, 151, 312-318.

99 J. J. Wouters, J. J. Lado, M. I. Tejedor-Tejedor, R. Perez-Roa and M. A. Anderson, Electrochim. Acta, 2013, 112, 763-773.

100 A. G. El-Deen, N. A. M. Barakat, K. A. Khalil, M. Motlak and H. Y. Kim, Ceram. Int., 2014, 40, 14627-14634.

101 H. B. Li, Z. Y. Leong, W. H. Shi, J. Zhang, T. P. Chen and H. Y. Yang, RSC Adv., 2016, 6, 11967-11972.

102 C. Y. Yin, M. K. Aroua and W. M. A. W. Daud, Sep. Purif. Technol., 2007, 52, 403-415. 
103 W. Huang, Y. M. Zhang, S. X. Bao, R. Cruz and S. X. Song, Desalination, 2014, 340, 67-72.

104 R. Niu, H. B. Li, Y. L. Ma, L. J. He and J. Li, Electrochim. Acta, 2015, 176, 755-762.

105 T. T. Wu, G. Wang, Q. Dong, B. Q. Qian, Y. L. Meng and J. S. Qiu, Electrochim. Acta, 2015, 176, 426-433.

106 M. M. Maroto-Valer, I. Dranca, T. Lupascu and R. Nastas, Carbon, 2004, 42, 2655-2659.

107 P. Hojati-Talemi, L. D. Zou, M. Fabretto and R. D. Short, Electrochim. Acta, 2013, 106, 494-499.

108 C. L. Yeh, H. C. Hsi, K. C. Li and C. H. Hou, Desalination, 2015, 367, 60-68.

109 A. M. Dehkhoda, E. Gyenge and N. Ellis, Biomass Bioenergy, 2016, 87, 107-121.

110 Y. B. Ji, T. H. Li, L. Zhu, X. X. Wang and Q. Lin, Appl. Surf. Sci., 2007, 254, 506-512.

111 D. Wang, C. Li, J. Guo and T. Li, Desalin. Water Treat., 2016, 57, 17731-17737.

112 J. H. Lee, H. J. Ahn, D. Cho, J. I. Youn, Y. J. Kim and H. J. Oh, Carbon Letters, 2015, 16, 93-100.

113 B. Q. Qian, G. Wang, Z. Ling, Q. Dong, T. T. Wu, X. Zhang and J. S. Qiu, Adv. Mater. Interfaces, 2015, 2, 1500372.
114 B. H. Min, J. H. Choi and K. Y. Jung, Electrochim. Acta, 2018, 270, 543-551.

115 P. Y. Liu, H. Wang, T. T. Yan, J. P. Zhang, L. Y. Shi and D. S. Zhang, J. Mater. Chem. A, 2016, 4, 5303-5313.

116 X. Gao, A. Omosebi, N. Holubowitch, A. Liu, K. Ruh, J. Landon and K. Liu, Desalination, 2016, 399, 16-20.

117 J. Y. Lee, S. J. Seo, S. H. Yun and S. H. Moon, Water Res., 2011, 45, 5375-5380.

118 J. S. Kim and J. H. Choi, J. Membr. Sci., 2010, 355, 85-90.

119 Y. J. Kim and J. H. Choi, Water Res., 2010, 44, 990-996.

120 Y. Liu, L. K. Pan, X. T. Xu, T. Lu, Z. Sun and D. H. C. Chua, Electrochim. Acta, 2014, 130, 619-624.

121 J. S. Kim, C. S. Kim, H. S. Shin and J. W. Rhim, Macromol. Res., 2015, 23, 360-366.

122 H. Yoon, J. Lee, S. R. Kim, J. Kang, S. Kim, C. Kim and J. Yoon, Desalination, 2016, 392, 46-53.

123 Y. Wang, L. W. Zhang, Y. F. Wu, S. C. Xu and J. X. Wang, Desalination, 2014, 354, 62-67.

124 Y. Wang, X. Y. Han, R. G. Wang, S. C. Xu and J. X. Wang, Electrochim. Acta, 2015, 182, 81-88.

125 H. Yoon, J. Lee, S. Kim and J. Yoon, Desalination, 2017, 422, 42-48. 